\title{
IX. „Vergangenheitsbewältigung“ und politische Kultur
}

Auch wenn die problematische Entwicklung der japanischen Erinnerungskultur prinzipiell bereits in den Jahren der Besatzungszeit angelegt war, gab es damals doch eine Reihe einschneidender Maßnahmen, die in eine andere Richtung deuteten. Da die bereits im Herbst 1945 eingesetzte japanische Regierungskommission zur Revision der Meiji-Verfassung es in ihrem Entwurf einer neuen Konstitution ablehnte, den Kaiser zu Gunsten des Parlaments zu entmachten und den Adel abzuschaffen, kam MacArthur Anfang $1946 \mathrm{zu}$ der Überzeugung, selbst handeln zu müssen - bevor die aus den Siegernationen gebildete Far Eastern Commission ihre Arbeit aufnehmen und ihm vermutlich ins Handwerk pfuschen würde. Nichts weniger als ein neues grundsätzliches Aufrollen der Kaiserfrage stand aus Sicht von SCAP nämlich zu befürchten. Deshalb hatte im Februar 1946 per ordre de général ein Stab der Besatzungsbehörde innerhalb einer Woche in Tag- und Nachtschichten einen Verfassungsentwurf auszuarbeiten, der nach den Prämissen MacArthurs das Feudalsystem beseitigen und die Grundlagen für einen ganz neuen Staatstypus, eine Art pazifistischer Erbmonarchie, legen sollte. Regierung und Hof in Tokio reagierten zwar schockiert auf das amerikanische Papier, doch rang sich Hirohito aus Furcht, doch noch als Kriegsverbrecher angeklagt zu werden, schließlich dazu durch, die faktisch von den Amerikanern oktroyierte, aber moderne demokratische Verfassung zu akzeptieren ${ }^{1}$. Nur nach außen hin verabredete man sich, um den Erfolg der Unternehmung nicht zu gefährden, auf eine Sprachregelung, die das Verfassungsprojekt als ein japanisches darstellte. Die am 3. November 1946 vom Tennô verkündete Konstitution trat sogar an einem 3. Mai (1947) in Kraft, also am Geburtstag des Meiji-Kaisers, um sie in die Tradition der japanischen Monarchie zu rücken.

Auch der berühmte Artikel 9, der eine radikale Konsequenz aus den militaristischen Verirrungen Nippons zog, fand auf Druck der Besatzungsmacht in die Verfassung Eingang, ging also mit hoher Wahrscheinlichkeit nicht auf eine Initiative des Ministerpräsidenten Shidehara Kijûro zurück; auch wenn Shidehara ebenso wie MacArthur später behauptete, der Japaner 
habe bei einem Gespräch im Januar 1946 eine derartige Bestimmung von sich aus angeboten. Tatsächlich aber paßte eine solche Initiative kaum zum politischen Charakter Shideharas, der zwar als erklärter Pazifist, aber eben auch als „realistischer Idealist“ galt ${ }^{2}$, jedenfalls nicht so illusionär war, um die Gefahren einer einseitigen Abrüstung seines Landes in einer vor Waffen starrenden Welt zu verkennen. Vieles spricht dafür, daß Shidehara - um MacArthur zur Nachsicht gegenüber dem Tennô zu bewegen - mehrfach vage Bemerkungen über die Wünschbarkeit eines Endes aller Kriege machte, die der General begierig aufgriff und von seinem Stab scharf akzentuieren ließ $3^{3}$. Bei MacArthur spielte auch hier wieder der Wunsch hinein, das vor allem wegen seiner militaristischen Auswüchse bei den übrigen Siegermächten übel beleumdete Kaisertum zu retten. Indem man am neuralgischen Punkt einen radikalen Schnitt führte, konnte der Organismus der Monarchie selbst am Leben erhalten werden. „Das japanische Volk“, so hieß es schließlich im Artikel 9, „wünscht aufrichtig einen internationalen Frieden, der auf Gerechtigkeit und Ordnung basiert, und verzichtet für immer auf den Krieg als Mittel der Staatsgewalt und auf die Drohung mit Waffengewalt sowie die Anwendung von Waffengewalt als Mittel zur Lösung internationaler Streitigkeiten. Um obiges Ziel zu erreichen, unterhalten wir weder Land-, See- noch Luftstreitkräfte oder andere Kriegskräfte ..."4. Ein im Entwurf der Konstitution zunächst enthaltener Passus, der Japan sogar explizit auf das Recht verzichten ließ, sich selbst zu verteidigen, und der die im Kalten Krieg dann bald vorgenommene weite Auslegung der Verfassung verhindert hätte, wurde als zu radikal verworfen. Die japanische Öffentlichkeit reagierte auf die Antikriegsklausel so zustimmend wie es ihre amerikanischen Urheber erhofft hatten: „Von Anfang an war der Stolz erkennbar, nun auf dem Felde des Völkerrechts und der Moral eine Führungsrolle zu übernehmen. Es hat der Seele des gedemütigten Volkes geschmeichelt, wieder ein Vorbild für die Weltgemeinschaft geworden zu sein. “5

Die hinter dem Antikriegsartikel stehenden Überlegungen spielten auch bei der Bodenreform eine wichtige Rolle, galt doch das „parasitäre Grundbesitzertum" neben den zaibatsu als ökonomische Basis des japanischen Militarismus ${ }^{6}$. Nachdem ein allzu zaghafter japanischer Entwurf den USA die angestrebte Demokratisierung auf dem Lande nicht zu gewährleisten schien, setzten sie auch hier eigenes, nachgerade revolutionäres Recht. Es ließ seit Februar 1946 vor allem durch die Begrenzung des Bodenbesitzes auf in der Regel knapp 1 ha, ab Oktober 1946 sogar noch etwas darunter,

2 Harries, Sheathing the Sword, S. 215.

3 Zur etwas mysteriösen Entstehungsgeschichte der "no-war clause“ siehe Harries, Sheathing the Sword, S. 213-216, und Finn, Winners in Peace, S. 103.

4 Zit. nach R. Hartmann, Geschichte des modcrnen Japan, S. 215.

5 Scharlau, Der General und der Kaiser, S. 76.

6 R. Hartmann, Geschichte des modernen Japan, S. 216. 
Familienangelegenheiten (etwa běi Heirat und Vermögensfragen) beseitigte $^{8}$, aber auch das aus der Feudalzeit überkommene Erbfolgesystem tilgte und die Rechte der Frau stärkte. Die Möglichkeit z.B., sich scheiden zu lassen, bisher Privileg des Mannes, wurde nun auch der Frau eingeräumt. Schließlich wurde selbst die Schrift reformiert, da die Schaffung einer demokratischen Öffentlichkeit so lange unmöglich schien, wie viele Erwachsene kaum in der Lage waren, die im komplizierten Kanji (den „Chinesischen Zeichen für den allgemeinen Gebrauch“) gedruckten Zeitungen ohne den Gebrauch eines Lexikons zu verstehen. Statt einer völligen Abschaffung der chinesischen Schriftzeichen und der Übernahme des westlichen Schreibstils, der von einigen amerikanischen Sprachreformern vehement gefordert wurde, kam es zum Kompromiß in Form einer Begrenzung der Schriftzeichen'.

$\mathrm{Ob}$ die von der Besatzungsmacht inaugurierten politischen Strukturreformen in Westdeutschland weiter reichten oder weniger weit als in Japan, ist zunächst eine Frage des Vergleichsmaßstabes. Der Bruch mit dem bis 1945 herrschenden System fiel im ersteren Fall schärfer aus, wobei allerdings zugleich auf - modifizierte - republikanische Traditionsbestände aus der Weimarer Zeit aufgebaut wurde. Die Frage der Monarchie war in Deutschland ohnehin schon 1918/19 negativ beantwortet worden, auch letzte postfeudale Relikte wurden noch in den 1920er Jahren mit der Auflösung der ostelbischen Gutsbezirke abgeräumt bzw. in ihren möglichen Nachwirkungen spätestens mit der Massenvertreibung der Deutschen aus ihrer Heimat östlich von Oder und Neiße gegenstandslos. Da die Beratungen über eine Verfassung im künftigen deutschen Weststaat zudem mehr als

7 Vgl. Halliday, Japan, S. 144 ff.; Fulkui, Postwar politics, S. 177. Weiterführend Dore, Land Reform in Japan; Hewes, Japan - Land and men.

8 Nicht zuletzt Kawashima Takeyoshi hatte in seinen Aufsätzen 1946 darauf hingewiesen, daß der moralische Zwang zur Unterwerfung unter die Autorität des Familienoberhauptes das schwerwiegendste Hindernis bei der demokratischen Neugestaltung Japans darstelle. Kawashima, Dic familiale Struktur der japanischen Gescllschaft.

9 Per Regierungserlaß wurde ihre Zahl zumindest auf 1850 begrenzt, ein Teil von ihnen in der Schreibweise vereinfacht und eine Silbenschrift-Orthographie eingeführt. Allerdings fanden selbst in populären Zeitschriften dennoch weiterhin mehr als 3000 Schriftzeichen Verwendung. Vgl. Rosenzweig, Erziehung, S. $153 \mathrm{ff} . ;$ R. Hartmann, Geschichte des modernen Japan, S. 216; Tsuchimochi, Education Reform, S. $108 \mathrm{ff}$. 
zwei Jahre später als in Japan - mit den Londoner Empfehlungen der Westalliierten im Sommer 1948 - begannen, also nach Ausbruch des Kalten Krieges, stellte sich auch die Option einer fundamental-pazifistischen Konstitution nicht mehr in der selben Ernsthaftigkeit wie in Japan.

Auch wenn sich die Abgeordneten im Parlamentarischen Rat bei ihren Verfassungsberatungen darüber bewußt waren, daß die Militärgouverneure ein wachsames Auge auf den Fortgang der Debatte hatten, war deren Rolle schon deshalb viel weniger ausschlaggebend, ja viel passiver als die der Besatzungsmacht in Japan, weil im westdeutschen Fall die Interessen der USA mit denen Großbritanniens und Frankreichs zur Deckung gebracht werden mußten - und dies erwies sich nicht zuletzt wegen der unterschiedlichen parteipolitischen Couleur der beteiligten Regierungen mitunter als recht mühsam. In einigen der zentralen Fragen: welche Lehren aus der jüngsten Vergangenheit zu ziehen seien, bedurften die deutschen Politiker ohnehin sehr viel weniger der Nachhilfe als ihre japanischen Kollegen. Von den Vätern und Müttern des Grundgesetzes war während der NS-Zeit kaum einer „vor machtstaatlichen Übergriffen, Denunziation und Verfolgung“ verschont geblieben ${ }^{10}$. So schien die Erinnerung an die Diktatur, aber auch an die verfassungspolitischen Defizite der Weimarer Republik, die Hitlers Machtergreifung nach verbreiteter Überzeugung erst ermöglicht hatten, schier allgegenwärtig ${ }^{11}$. Im Bereich der politischen Symbolik war es bezeichnend, daß der von der Deutschen Partei vorgeschlagene Name „Deutsches Reich“ (mit dem Zusatz „Bund Deutscher Länder“), der die nationale Kontinuität betonte, sich nicht durchsetzte, obwohl etwa auch Jakob Kaiser (CDU) dafür plädierte. Einer Mehrheit schien der Begriff „Bundesrepublik Deutschland" denn doch angemessener, nachdem Carlo Schmid (SPD) deutlich gemacht hatte, welch aggressiven Akzent das Wort „Reich“ wegen der Verbrechen des Dritten Reiches bei den Nachbarvölkern habe ${ }^{12}$. So lassen sich die grundlegenden politischen Strukturreformen in Westdeutschland und Japan nach 1945 zusammenfassend dahingehend deuten, daß die Deutschen mental offensichtlich einen radikaleren Bruch mit der Vergangenheit vollzogen und in der Distanzierung von ihr auch aus eigenem Antrieb weiter zu gehen bereit waren, als dies die Japaner - selbst unter dem Druck der Besatzungsmacht - wollten.

10 Feldkamp, Der Parlamentarische Rat, S. 42.

11 Fromme, Von der Weimarer Verfassung zum Bonner Grundgesetz, S. $24 \mathrm{ff}$.

12 Jakob Kaiser hatte geltend gemacht, im deutschen Volk würde in einigen Jahren wieder eine Bewegung lebendig werden, die erneut nach einem Reich rufe, falls jetzt auf den Namen „Reich“ verzichtet würde. Eschenburg, Jahre der Besatzung, S. 506. 


\section{Shintôistische und protestantische Erinnerungslandschaften}

Wer die noch in halbfeudalen Traditionen verwurzelten Japaner langfristig zu brauchbaren Demokraten umerziehen wollte, konnte schwerlich darauf verzichten, auch an die religiösen Grundlagen ihrer Mentalität zu rühren: den aufs engste mit kaiserlichem System und Militarismus verbundenen Staatsshintô. Hatte der Tennô während der Jahrhunderte der TokugawaHerrschaft ein Schattendasein in fast klösterlicher Abgeschiedenheit geführt, so war ihm in der fundamentalen Staatskrise nach der erzwungenen Landesöffnung in den 1860er Jahren die Rolle eines politischen Retters zugewachsen. Denn die notwendig scheinende Rückbesinnung auf die nationalen Ursprünge ließ sich durch eine gezielte Aufwertung des Tennô symbolisch verstärken. Im Zuge dessen war es zu einer Renaissance des vom Buddhismus zurückgedrängten shintôistischen Glaubens gekommen ${ }^{13}$, der wie eine Stammesreligion die politische Überzeugung von der kulturellen Einzigartigkeit Nippons religiös zu untermauern vermochte. Denn die in den Schreinen verehrten Gottheiten (kami) hatten der Sage nach nicht etwa die ganze Welt erschaffen, sondern nur Japan, und auch nicht den Menschen, sondern nur den Japaner. Die besondere Bedeutung des Tennô resultierte dabei aus der Vorstellung, ein mythischer Urenkel der Sonnengöttin, der legendäre Jimmu-Tennô, habe am 11. Februar 660 (vor der christlichen Zeitrechnung) als erster den japanischen Thron bestiegen ${ }^{14}$. Die nationalistische Instrumentalisierung dieser Weltanschauung ist im kaiserlichen Erziehungsdekret weiter oben bereits dargelegt worden.

Die US-Besatzer sahen in dem seit der Meiji-Restauration zur ideologischen Basis des japanischen Nationalstaates gewordenen „Staats-Shintôismus“ - mit der Erklärung der bislang privaten Schreine zu „Kultstätten des Staates" und der Verbeamtung der Priester ${ }^{15}$ - mithin nicht ohne Grund ein „Instrument des Kaiserkults und der Versklavung der Sinne des japanischen Volkes“16. In der westlichen Öffentlichkeit war der Shintô sogar als „engine of war" charakterisiert und für den Fanatismus der kamikaze-Kämpfer verantwortlich gemacht worden ${ }^{17}$. MacArthur, ein tief religiöser Protestant episkopalischer Richtung, der neben Jesus Christus auch George Washington und Abraham Lincoln zu seinen wichtigsten Lehrern zählte und sich als Werkzeug der göttlichen Vorsehung fühlte, sah im Nachkriegsjapan ein spi-

13 Und das hieß faktisch auch: Säuberung des Shintô von buddhistischen Elementen, auch wenn eine Unterdrückung des Buddhismus nicht in der direkten Absicht der neuen Politik lag; aber er war für das Regime einfach nicht relevant. Im Ergebnis führte die jetzt durchgeführte Trennung von Shintô und Buddhismus zu einer - regional unterschiedlich massiven „antibuddhistischen Bilderstürmerei“. Lokowandt, Shintô, S. 48.

14 Vahlefeld, Japan, S. 150.

15 Vgl. Lokowandt, Shintô, S. 49.

16 Dokument 1, in: Benz, Amerikanische Besatzungsherrschaft, S. 281.

17 Hardacre, Shintô and the State, S. 134. 
rituelles Vakuum entstanden, das der Kommunismus füllen würde, wenn dies nicht dem Christentum gelang. Doch obwohl der General kirchliche Missionstätigkeit entschieden förderte, war die in seiner Radiobotschaft an den Kongreß im Februar 1947 behauptete Zahl von rund zwei Millionen zum Christentum konvertierten Japanern ebenso maßlos übertrieben wie die schlimmsten Befürchtungen shintôistischer und buddhistischer Führer vor einer Zwangsbekehrung der Japaner durch US-Missionare ${ }^{18}$.

Immerhin aber ordneten die Amerikaner - von Haus aus ohnehin zur klaren Trennung von Staat und Kirche neigend - zum Zwecke der „moralischen Abrüstung "19 an, die regierungsamtliche Unterstützung, Kontrolle und Verbreitung des Staatsshintô abzuschaffen. Selbst der Fujiyama, seit alters her Objekt shintôistischer Naturanbetung, durfte nicht mehr abgebildet werden, nachdem die Naturverehrung allzuoft in eine Vergottung des japanischen Staates umgeschlagen war. So mußte etwa eine Szene mit Bauern, die an den Hängen des Fujiyama arbeiteten, aus einem zeitgenössischen Spielfilm herausgeschnitten werden 20 . Vor allem aber stellte Kaiser Hirohito selbst in der Neujahrsbotschaft 1946 seine „Göttlichkeit“ in Frage: „Die Bande, die Uns und Unser Volk verknüpfen, haben immer auf gegenseitigem Vertrauen und gegenseitiger Anhänglichkeit beruht. Sie hängen nicht von Legenden und Mythen ab. Sie sind nicht zu folgern aus der falschen Auffassung, daß der Tennô göttlich ist und daß die Japaner anderen Rassen überlegen und etwa vom Schicksal bestimmt sind, die Welt zu beherrschen" 21 . Der zentrale Glaubenssatz, daß das japanische Kaiserhaus in der direkten und ungebrochenen Nachfolge der Sonnengöttin Amaterasu stehe, wurde in der Erklärung allerdings nicht erwähnt und somit auch nicht dementiert. Der alte Mythos blieb als Möglichkeit erhalten ${ }^{22}$.

Daraus erhellt, weshalb der Rücktritt des Tennô vom Throne eines „Gottes“ - anders als ausländische Stimmen prophezeiten - das Land keineswegs bis ins Mark erschütterte, sondern von den Japanern mehr oder weniger ignoriert wurde. Auch ein später vom Auswärtigen Amt in Tokio herausgegebener Lebenslauf des Kaisers befand die „Entgöttlichung“ keineswegs der Erwähnung für nötig. Kawai hat argumentiert, daß es zumindest für einen gebildeten Japaner ohnehin selbstverständlich gewesen sei, im Tennô keine gottähnliche Gestalt zu erblicken, sondern allenfalls eine über den anderen

18 Vgl. Woodward, The Allied Occupation of Japan, S. 241; Hardacre, Shintô and the State, S. 135.

19 Nishi, Unconditional Democracy, S. 59.

20 Dies galt in ähnlicher Weise für Filme mit Schwertkämpfern oder Samuraidramen, die in den Augen der US-Besatzungsbehörden einen feudalistisch-antidemokratischen Geschmack hatten. Buruma, Erbschaft, S. 70.

21 Zit. nach der deutschen Übersetzung von Vahlefeld, Japan, S. 268. Das gesamte Dokument sowie ein Bericht zu seiner Entstehungsgeschichte im Anhang der religionsgeschichtlichen Untersuchung von Woodward, The Allied Occupation of Japan, S. 315-319.

22 Scharlau, Der General und der Kaiser, S. 54. 
Menschen stehende Gestalt ${ }^{23}$. Für die Masse der Japaner aber galt dies kaum. Deshalb verdienen doch die Umstände Erwähnung, unter denen 1962 die Shintô-Universität zur Ausbildung des Priesternachwuchses, die bis Kriegsende dem Schrein der Sonnengöttin im Inneren des Heiligtums von Ise angegliedert gewesen war, in Anwesenheit des Ministerpräsidenten (!) wiedereröffnet wurde. Denn der Rektor bekannte bei dieser Gelegenheit, ohne einen Sturm des Protests in der Öffentlichkeit auszulösen, für ihn sei der Tennô - als Erbe von Blut und Thron der Sonnengöttin - weiterhin ein Gott; er sei Mensch und Gott zugleich ${ }^{24}$.

Die Wirkung der religionspolitischen Maßnahmen der Besatzungszeit wurde allgemein dadurch beeinträchtigt, daß der Shintô-Glaube das animistisch anmutende Weltbild der meisten Japaner nach 1945 weiterhin bestimmte, wenn auch mehr und mehr in gleichsam kulturshintôistischer Form und synkretistischer Mischung mit dem Buddhismus, dessen Reformsekten (Zen, Amida und Nichirin) seit dem 13. Jahrhundert in Japan weite Verbreitung gefunden hatten 25 . Zudem verfügte der Buddhismus nicht nur über besser ausgebildete Geistliche, sondern war auch weniger durch die Niederlage im Zweiten Weltkrieg diskreditiert als der Shintô, dem die allgemeinen Säkularisierungs- und Urbanisierungstendenzen in den Nachkriegsjahrzehnten besonders zusetzten ${ }^{26}$. Andererseits zeigte sich nach der „Entstaatlichung“ des Shintô die Zentrale der Körperschaft für die ShintôSchreine rasch in der Lage, die lokalen Schrein-Verwalter im ganzen Land über die neue Lage aufzuklären und Selbsthilfemöglichkeiten vorzuschlagen ${ }^{27}$, etwa Initiativen prominenter Bürger für lokale Religionsgemeinschaften ${ }^{28}$. Vor allem aber blieb der Tennô, traditionell „the object and primary practitioner of Shinto rituals "29, auch nach der neuen Verfassung „Symbol Japans und der Einheit des japanischen Volkes“30.

Zentrale Bedeutung für die „Vergangenheitsbewältigung“ gewann der Shintôismus auch deshalb, weil die Verehrung der Ahnen - von denen das Kaiserhaus nur ein wichtiger Teil ist - neben dem Ideal der Reinheit und der Harmonie mit der Natur zu den einzigen Forderungen dieser ansonsten ganz und gar undogmatischen, auf Glaubensbekenntnis und Sittenlehre verzichtenden „Religion“ gehört. Der sowohl shintôistisch als auch buddhi-

23 Kawai, Japan's American Interlude, S. 74; Schwentker, Die Grenzen der Entzauberung, S. 128.

24 Vahlefeld, Japan, S. 269.

$25 \mathrm{Vgl}$. Haasch, Die Religionen des heutigen Japan, vor allem S. $36 \mathrm{ff}$.

${ }^{26} \mathrm{Zu}$ entsprechenden „Verfallsdiagnosen“ siehe Hardacre, Shintô and the State, S. 142.

27 Schwade, Die staatliche Religionspolitik, S. 60. Heute gehören dem sogenannten „SchreinHauptamt e.V." mit 79000 Schreinen und mehr als 83 Millionen Gläubigen die Mehrheit aller shintôistischen Religionsgemeinschaften an.

28 Vgl. hierzu auch Montgomery, Forced to be Free, S. 153.

29 Ebd., S. 60.

30 Vgl. Nishi, Unconditional Democracy, S. 124. Vertiefend Antoni, Der himmlische Herrscher und sein Staat. 
stisch geprägte Ahnenkult, in dessen Mitte die Familie steht, geht von einem Einfluß der Verstorbenen auf das irdische Geschehen aus. Jedes Jahr im August, wenn überall im Land das populäre Bon'odori-Fest gefeiert wird, kehren die Toten als Gäste auf die Erde zurück und wollen mit Tanz und Musik unterhalten werden. Nicht Trauer, sondern Freude bestimmt dieses japanische Allerseelen-Fest. Andererseits errichten große Autohersteller Kultstätten, an denen die unruhigen Seelen von bei Verkehrsunfällen Getöteten „ausgesöhnt und von Rachegelüsten abgehalten werden sollen“31. Und so bedürfen nach shintôistischer Vorstellung besonders auch die Seelen der meist in jugendlichem Alter gefallenen Soldaten, die einen „schlimmen Tod“ gestorben waren, sorgfältigster Behandlung, weil sie sonst nicht zur Ruhe kämen und die Staatsfamilie bedrohten. Klaus Antoni hat darauf hingewiesen, daß das archaischen ozeanischen Kulturvorstellungen entspringende Bedürfnis, die rächenden Seelen der „schlimmen Toten “ $z u$ besänftigen und buchstäblich „unschädlich“ zu machen, das genaue Gegenteil von Heldenverehrung darstelle. Dies sei auch beim Urteil über den Yasukuni-Schrein $\mathrm{zu}$ berücksichtigen, jedenfalls solange dieser seiner religiösen Bedeutung nicht entkleidet würde und der shintôistische Volksglaube nicht zum Erliegen käme ${ }^{32}$. Tatsächlich boten die Riten der dortigen Totenverehrung auch ganz privatem, unpolitischen Gedenken einen Ort und eben nicht nur „einer kollektiven, ultrakonservativen Ideologie“33.

In den Augen vieler Kritiker dagegen stand bzw. steht der vom Staat seit 1869 unterhaltene Yasukuni-Schrein in Tokio, in dem die für den Tennô gefallenen Soldaten als Götter verehrt werden, für die Symbiose von Militarismus und Shintôismus ${ }^{34}$. Die US-Besatzer hatten im Rahmen ihrer Politik der Trennung von Staat und Religion nach 1945 zwar versucht, die in diesem allerheiligsten Schrein praktizierte Verehrung der Seelen auch von Teilnehmern eines Angriffskrieges zu unterbinden. Zumindest Gravuren japanischer Kriegshelden und Schlachten auf den riesigen Bronzelaternen vor dem Hauptschrein mußten von den Yasukuni-Priestern mit Beton überstrichen werden. Doch bereits 1948 nahm der Tennô, das von den USA unangetastet gelassene höchste Objekt shintôistischer Verehrung, seine bis Kriegsende üblichen alljährlichen Besuche des Schreins wieder auf. In den 1950er Jahren forderten kleinere reaktionäre Gruppen, aber auch die japanischen Konservativen (LDP), getrieben von der millionenstarken Vereinigung der Familien der Kriegsopfer, dann immer offener, Politik und Religion wieder zu koppeln und den Schrein zur offiziellen Kultstätte zu machen. Beim

31 Kreiner, Religionen heute, S. 528. Vgl. auch ders., Religion in Japan, sowie ders., The Impact of Traditional Thought on Present Day Japan.

32 Zum Yasukuni-Schrein siehe Antoni, Yasukuni und der „Schlimme Tod“ des Kriegers, vor allem S. 183, 187, 189.

33 Seraphim, Im Dialog mit den Kriegstoten, S. 14.

34 Grundlegend hierzu Lokowandt, Zum Verhältnis von Staat und Shintô, vor allem S. $173 \mathrm{ff}$. 
jährlichen Hauptfest des Schreins fuhren Premierminister und Minister jetzt zumindest „privat“ wieder vor, und 1957 wurde auch der Betonüberstrich von den martialischen Gravuren der Bronzelaternen entfernt ${ }^{35} .1959$ war die Einsegnung von zweieinhalb Millionen im Weltkrieg gefallener Japaner in den Yasukuni-Schrein nahezu abgeschlossen, wobei in zwei Schüben auch über 800 hingerichteten Kriegsverbrechern der Kategorie B und C dieses Ritual zuteil wurde. Nach einem weiteren Schub im Oktober 1966 (114 Fälle) waren schließlich alle exekutierten Kriegsverbrecher eingesegnet - abgesehen von den sieben zum Tode Verurteilten des Tokioter Prozesses, deren Aufnahme in den Schrein Mitte der 1970er Jahre aber heimlich erfolgte ${ }^{36}$.

Ganz offen wurde dieser Gruppe schon viel früher, 1960, auf Initiative einiger japanischer Strafverteidiger im Tokioter Prozeß auf dem Gipfel des Berges Sangane ein „Grabmal für die sieben fürs Vaterland gestorbenen Helden" errichtet, das sich seitdem mehr und mehr zu einer Pilgerstätte shintôistischer Veteranenverehrung auswuchs. Auf einem 1985 daneben aufgestellten Gedenkstein ist ein Gedicht „Zum Gedenken an die zu Märtyrern gewordenen sieben Kameraden“ zu lesen, das der als Kriegsverbrecher der Kategorie A zu lebenslanger Haft verurteilte Generalleutnant Ôshima Hiroshi verfaßt hatte: „Die Rache für die Ungerechtigkeit kehrt in die uralten Zeiten zurück. Eines Tages werden wir die falsche Anklage hinwegfegen und die treuen Seelen beruhigen." 37

Die anhaltenden Bemühungen um eine neuerliche Verstaatlichung des Yasukuni-Schreins, für die schon 1964 über sechseinhalb Millionen Unterschriften gesammelt worden waren, erreichten am 30. Juni 1969 einen Höhepunkt: Rechtsgerichtete LDP-Abgeordnete brachten am 100. Jahrestag der Gründung des Schreins einen entsprechenden Gesetzesentwurf ein, um „das Gefühl der Verehrung des Volkes gegenüber den Seelen der im Kriege Gefallenen sowie der Menschen, die ihr Leben für ihr Land geopfert haben, auszudrücken, ihrer bleibenden Verdienste zu gedenken, sie zu beschwichtigen und zum Ruhme ihrer Taten Zeremonien, Feiern usw. durchzuführen und dadurch ihr hohes Verdienst auf ewig der Nachwelt im Gedächtnis zu bewahren." 38 Das Vorhaben stieß allerdings auf heftigen Widerstand, weil es nicht nur in erinnerungskultureller Hinsicht bedenklich schien, sondern noch dazu an die laizistischen Grundlagen der Nachkriegsverfassung rührte. Die „Kräfte zur Unterstützung der Verfassung“, eine Regenbogenkoalition aus Pazifisten, Gewerkschaftern, Buddhisten, Christen, Vertretern der sogenannten neuen Religionen und Politikern der nicht konservativen

35 Inoue, Geschichte Japans, S. 620; Buruma, Erbschaft, S. 85.

36 Tanaka, Japans Nachkriegsverantwortung, S. 406 f.; Seraphim, Im Dialog mit den Kriegstoten, S. 21.

37 Zit. nach Tanaka, Japans Nachkriegsverantwortung, S. 408.

38 Seraphim, Im Dialog mit den Kriegstoten, S. 21. 
Parteien, brachte das Projekt 1974 schließlich zu Fall39. Seine Befürworter änderten allerdings nun ihre Strategie und setzten sich zum Ziel, zumindest "offizielle Besuche" des Schreins durch den Tennô und die Staatsregierung möglich zu machen. Nachdem ihre Kampagnen an der Basis Erfolg hatten37 von 47 Präfektur-Parlamenten faßten 1983 einen unterstützenden Beschluß - und auch die neu gegründete "Gesellschaft zur Verehrung der Geister der gestorbenen Soldaten durch aktives Handeln“ unter dem Vorsitz des ehemaligen Präsidenten des Obersten Gerichtshofs in diese Richtung agierte $^{40}$, hielt das Kabinett Nakasone die Zeit für gekommen, „einen Schlußstrich unter die Nachkriegspolitik“ zu ziehen und dem YasukuniSchrein zum Jahrestag der Kapitulation am 15. August 1985 endlich auch einen sorgfältigst vorbereiteten „offiziellen Besuch“ abzustatten.

„In einem schwachen Bemühen, die Observanz religiöser Obertöne loszuwerden“, opferten der Premierminister und seine Minister statt der üblichen Shintô-Gabe von Zweigen des heiligen Sakaki-Baumes nur Blumen und verbeugten sich weniger oft, als dies die Schrein-Liturgie an sich vorschrieb $^{41}$. Doch ließen die Äußerungen des hochkonservativen Nakasone Yasuhiro wenig Zweifel an seinen Intentionen aufkommen, gab er sich doch überzeugt, „daß das Volk denjenigen, die sich für ihr Vaterland geopfert haben, seinen Dank“ auszudrücken habe ("wer würde denn sonst noch sein Leben für sein Land hergeben?" $)^{42}$. Unbeschadet heftiger Proteste gegen den offiziellen Schrein-Besuch schätzte Nakasone die Wirkung seines Schrittes bei der Mehrheit der japanischen Wähler („Wenn ich es nicht tue, kann sich die LDP nicht halten "43) richtig ein, die ihm und seiner Partei bei den folgenden Wahlen zum Unter- und Oberhaus einen überwältigenden Sieg bescherten.

Nakasones Überzeugung, der Yasukuni-Schrein sei so etwas wie der nationale Soldatenfriedhof der Amerikaner in Arlington, ging schon deswegen an der Wirklichkeit vorbei, weil dort Geistliche jeder Religion bei Gedenkriten zelebrieren können, während der Schrein eine ausschließlich dem Shintô vorbehaltene Einrichtung ist. Würden sich die erinnerungskulturellen Bemühungen der Tokioter Regierung auf japanische Orte konzentrieren, die dem Arlington National Cemetery am ähnlichsten sind, wie das nicht als religiöse Einrichtung registrierte - Grabmal des unbekannten Soldaten in Chidorigafuchi ${ }^{44}$ oder der Friedenspark in Hiroshima, würden

39 Yagyû, Der Yasukuni-Schrein, S. 250.

40 Ebd., S. 251.

41 Hardacre, Shintô and the State, S. 151.

42 Tanaka, Japans Nachkriegsverantwortung, S. 389.

43 So Nakasone auf Bedenken von Beratern wegen außenpolitischer Rückwirkungen seiner Aktion in Südkorea und China. Ebd., S. 390.

44 Das Grabmal war 1959 gegen den Widerstand der Priester des Yasukuni-Schreins errichtet worden, um aller im Zweiten. Weltkrieg gefallenen Soldaten zu gedenken. 
auch kaum so erbitterte Kontroversen aufkommen ${ }^{45}$. Nur läßt sich fragen, ob nicht gerade durch diese Polarisierung der gewünschte wahlstrategische Effekt im Sinne einer Mobilisierung der LDP-Stammwähler erzielt wurde. Der 1947 gegründete LDP-nahe Verband der Kriegshinterbliebenen (Nibon izokukai), der die sozialen Interessen von acht Millionen Menschen vertrat, hatte jedenfalls von Anfang an eine Zweigstelle am Yasukuni-Schrein unterhalten und Nachrichten über das Ergehen dieser Einrichtung im Verbandsblatt publiziert ${ }^{46}$.

„Yasukuni“ heißt so viel wie „der Nation Frieden bringen“. Die Art und Weise wie das im einzigen großen Kriegsmuseum des Landes am YasukuniSchrein und in seinen regionalen Zweigstellen, den „Schreinen zum Schutz des Landes " 47 , geschieht, kommt dem westlichen Besucher bis heute sehr fremd vor. Weiße Schildchen auf den Kirschbäumen vor dem Schrein tragen die Namen von Regimentern oder Kriegsschiffen der Kaiserlichen Armee. Hinter dem Schrein ist ein Gedenkstein für die kempeitai errichtet worden, und in den Sälen des Museums sind militärische Devotionalien aller Art von Gemälden mit „menschlichen Torpedos“ bis zu blutbefleckten Kriegsfahnen zu sehen, wobei die Texte zu den Ausstellungsstücken oft apologetischen Charakter haben. Die Annexion der Mandschurei 1931 wird etwa gerechtfertigt als Kampf gegen sowjetischen Kommunismus, aber auch gegen chinesische Rebellen, die von Engländern und Amerikanern zu antijapanischen Handlungen aufgestachelt worden seien. Der historischen Wirklichkeit entsprechend von einem Invasionskrieg zu sprechen, wäre nach Überzeugung der Shintô-Priester schon aus Rücksicht auf „die Gefühle der hier bewahrten Seelen und ihrer Familien“ unmöglich: „Wir müssen dafür sorgen, daß sie glücklich bleiben". ${ }^{48}$ Die Japaner, so hat der Publizist Etô Jun dazu bemerkt, würden sich von anderen Völkern eben dadurch unterscheiden, daß sie mit den Toten leben; darum sei der Yasukuni-Schrein lebenswichtig für die Kontinuität der japanischen Nation ${ }^{49}$.

Die shintôistisch motivierten Formen des Umgangs mit dem „schlimmen Tod" stehen in einem denkbar krassen Gegensatz zu der von einer ganz anderen „Betroffenheit“ zeugenden Auseinandersetzung der christlichen Kirchen in Deutschland mit der historischen Erblast. Allerdings gilt dieser Befund in erster Linie für den Protestantismus, der aufgrund seiner viel engeren historischen Verstrickungen in Deutschnationalismus und dann auch Nationalsozialismus tatsächlich ungleich mehr zu bewältigen hatte ${ }^{50}$. Der

45 Hardacre, Shintô and the State, S. 141, 159.

46 Seraphim, Im Dialog mit den Kriegstoten, S. $17 \mathrm{f}$.

47 Vgl. hierzu Lokowandt, Shintô, S. 62.

48 Buruma, Erbschaft, S. 280 ff., Zitat S. 284.

49 Vgl. ebd., S. 279.

50 Zum nationalprotestantischen Milieu vgl. auch Kittel, Provinz zwischen Reich und Republik. 
deutsche Katholizismus bekam dagegen bereits am 2. Juni 1945 von Papst Pius XII. ein ehrenhaftes Zeugnis ausgestellt, weil es „Millionen tapferer Katholiken“ auch in den letzten Kriegsjahren nie unterlassen hätten, „mutig und ernst ihre Stimme zu erheben" 51 . Damit war die Linie vorgegeben, auf der sich die Fuldaer Bischofkonferenz am 23. August 1945 mit einem Hirtenbrief bewegte, der indes viel weniger Aufmerksamkeit fand als die Stuttgarter Erklärung. Dem eigentlichen Schuldbekenntnis wurde im Fuldaer Text eine Darstellung katholischer Resistenz gegen den Nationalsozialismus vorangestellt: „Katholisches Volk, wir freuen uns, daß du dich in so weitem Ausmaße von dem Götzendienst der brutalen Macht ferngehalten hast ... ". Erst anschließend wurde das Furchtbare, das „während des Krieges durch Deutsche in den besetzten Gebieten geschehen" ist, zutiefst beklagt und eingeräumt, daß sich auch viele Katholiken „von den falschen Lehren des Nationalsozialismus“ hätten „betören“ lassen und daß viele gegenüber den Verbrechen "gleichgültig geblieben" 52 seien oder ihnen durch ihr Verhalten sogar Vorschub geleistet hätten. Diesem Eingeständnis nicht kollektiver, sondern differenzierter Schuld folgte zudem das Aufzeigen von Entlastungsgründen etwa für Beamte und Lehrer, bei denen Parteizugehörigkeit oft keine innere Zustimmung zu den Taten des Regimes bedeutet habe.

Die Gründe für den eher rechtfertigenden Ton des Fuldaer Hirtenwortes sind letztlich im katholischen Verständnis von Sünde und Erbsünde und ihrer Wirkung auf die menschliche Natur zu suchen. Während die evangelische Theologie - vereinfacht gesagt - von der durch die Erbsünde bedingten völligen Verderbtheit der menschlichen Natur ausgeht, die das Gute nicht aus eigener Willenskraft, sondern allein durch die Gnade Gottes vermöge, wobei Sündhaftigkeit folglich auch ein Zustand und nicht nur auf ein moralisch verwerfliches Verhalten zurückzuführen ist, geht die katholische Theologie von einer trotz Erbsünde bestehen bleibenden Freiheit des menschlichen Willens aus. Erbsünde bedinge lediglich eine Disposition zum Bösen, einen Defekt, nicht aber grundsätzliche Verderbnis. Katholisches Schuldeingeständnis zieht also viel stärker den moralischen Kern der Persönlichkeit in Mitleidenschaft, weist - anders als ein verbreitetes konfessionelles Vorurteil vermuten ließe - dem Individuum einen höheren Stellenwert zu und seiner Schuld ein im einzelnen stark zu differenzierendes Ausmaß. Demzufolge wird im Fuldaer Bischofswort zwischen der Unterlassensschuld der Mehrheit (auch des katholischen Kirchenvolkes) und der aktiveren Schuld der Eliten unterschieden, während die Stuttgarter Schulderklärung der EKD vom Oktober 1945 dies nicht tut ${ }^{53}$.

51 Zit. nach Bücker, Die Schulderklärungen der (deutschsprachigen) Kirchen, S. 372 f.

52 Ebd., S. 359.

53 Ebd., S. 373 f., sowie Rustmeier, Sünde und Schuld. 
Die Entstehungsgeschichte des ersten evangelischen Kirchenwortes zur deutschen Schuld ist nur vor dem Hintergrund des internationalen Einflusses des im Aufbau begriffenen Ökumenischen Rates der Kirchen zu verstehen, dessen niederländischer Generalsekretär im Juli 1945 in einem Brief an den Berliner Bischof Otto Dibelius darauf hingewiesen hatte, daß vor einer Wiederaufnahme der Deutschen in die ökumenische Weltgemeinschaft gewichtige Schwierigkeiten zu überwinden seien, „besonders bei den Kirchen, die so tief gelitten haben unter der deutschen Besatzung“. Sehr viel leichter würde dies fallen, wenn die deutschen Protestanten ein offenes Wort „nicht nur über die Missetat der Nazis, sondern auch besonders über die Unterlassungssünden des deutschen Volkes, einschließlich der Kirchen" sprächen ${ }^{54}$. Im evangelischen Kirchenvolk entbrannten zunächst außerordentlich leidenschaftliche Debatten um das Schuldgeständnis, weil es teilweise als Bekenntnis zur deutschen Kollektivschuld verstanden wurde und - wie u.a. der Theologe Helmut Thielicke monierte - von der Schuld der anderen schwieg55. Rückhaltlose Schuldbekenntnisse forderte vor allem der kleine bruderrätliche Flügel der Bekennenden Kirche, während die meisten konservativen Lutheraner - eher auf der Linie des Fuldaer Bischofswortes - das Unrechtsgeschehen auf eine kleine Gruppe nationalsozialistischer Verbrecher zu fokussieren suchten, deren Verführungskraft die große Mehrheit Gutgläubiger erlegen sei. Unübersehbar war ferner die zeitweilige Konzentration des protestantischen Engagements auf die unter der alliierten Entnazifizierungspolitik leidenden Deutschen - bis hin zu zahlreichen Gnadengesuchen kirchenleitender Persönlichkeiten für NS-Verurteilte ${ }^{56}$. Dennoch aber entwickelte die Stuttgarter Erklärung in ihrer Nähe zur Kollektivschuld langfristig eine Eigendynamik ${ }^{57}$, die bereits während der AdenauerZeit in der Erinnerungspolitik der evangelischen Kirchen deutlich spürbar wurde.

War die Schulderklärung von 1945 auf das Verhältnis von Christen und Juden nach der Shoah nicht explizit eingegangen, so verabschiedete die EKD-Synode am 27. April 1950 angesichts neuerlicher antisemitischer Tendenzen ein Wort „zur Schuld an Israel“ und warnte alle Christen, „das, was über uns Deutsche als Gericht Gottes gekommen ist, aufrechnen zu wollen gegen das, was wir an den Juden getan haben; denn im Gericht sucht Gottes Gnade den Bußfertigen. " 58 Es blieb auch keineswegs bei wenigen papiernen Erklärungen, vielmehr gewann das Thema der „unbewältigten Vergangenheit" spätestens bis Mitte der 1950er Jahre vor allem auf zeithistorischen Tagungen Evangelischer Akademien, in den Begegnungsräumen von Ge-

\footnotetext{
54 Boyens, Das Stuttgarter Schuldbekenntnis, S. 388.

55 Greschat, Die Schuld der Kirche, S. $180 \mathrm{ff}$.

56 Vgl. hierzu Besier, Die politische Rolle des Protestantismus in der Nachkriegszeit.

57 So auch Greschat, Die Schuld der Kirche, S. 315.

58 Heidtmann, Hat die Kirche geschwiegen?, S. 94.
} 
schichtswissenschaft, Volksbildung und kirchlich-theologischem Engagement zunehmend an Bedeutung, womit nach den Worten des Berliner Akademieleiters Erich Müller-Gangloff einem Mangel an Literatur über Hitler und einer geringen Verbreitung der wenigen einschlägigen Werke aufgrund des Vorwurfs der „Nestbeschmutzung“ begegnet werden sollte. In den Diskussionsbeiträgen des Deutschen Evangelischen Kirchentages in Frankfurt im Sommer 1956 war das Thema „Vergangenheitsbewältigung“ wiederum derart präsent, daß daraus sogar auf die genuin protestantische Prägung des Begriffes geschlossen worden ist ${ }^{59}$. Anläßlich der großen NS-Verbrecherprozesse im Jahr 1963 forderte der Rat der EKD mit größerem Nachdruck denn je dazu auf, das Ausmaß der „von deutschen Menschen mit staatlichen Gewaltmitteln geplanten, befohlenen und unbeschreiblich grausam ausgeführten Massenverbrechen endlich zur Kenntnis zu nehmen“. Von Nestbeschmutzung könne „nur Unverstand ... reden, wo es in Wahrheit darum geht, ein schwerbeschmutztes Nest zu säubern“; denn es „waren die Irrwege unseres ganzen Volkes und die Versäumnisse von uns Christen“60.

Der Ton, der jetzt anklang, stand im Zeichen eines tiefgreifenden Wandlungsprozesses des deutschen Protestantismus, in dem sich zwei Entwicklungen wechselseitig beeinflußten und verstärkten. Zum einen der bislang größte politisch-kulturelle Bewältigungsschub infolge einer Welle von $\mathrm{Ha}$ kenkreuzschmierereien um 1959/6061 sowie neuer großer NS-Prozesse; zum anderen das nach der Zäsur des Berliner Mauerbaus am 13. August 1961 unübersehbare Dahinschwinden auch der letzten Hoffnungen auf eine baldige Wiedervereinigung mit den Glaubensbrüdern und -schwestern in den mitteldeutschen Kernlanden des Protestantismus, die über die kirchenpolitischen Flügel hinweg eineinhalb Jahrzehnte lang mit heißem Herzen erstrebt worden war. Wie um die maßlos enttäuschten nationalen Sehnsüchte innerlich zu verarbeiten und den unabwendbar gewordenen Status quo ethisch zu legitimieren, rekurrierten die Kirchenleitungen nunmehr verstärkt auf den gesamtgesellschaftlich ohnehin immer wichtiger werdenden Topos der deutschen Schuld statt weiterhin von der „sittliche(n) Notwendigkeit" der Wiedervereinigung zu sprechen ${ }^{62}$ und - wie noch die EKD-Synode anläßlich des Eichmann-Prozesses 1961 - zu betonen: „Keine Schuld ist so groß, daß sie ausgenommen wäre von der Vergebung Gottes ...63. Zu dieser Entwicklung trug auch die Gründung einer evangelischen Arbeitsgemeinschaft "Juden und Christen" auf dem Kirchentag in Berlin 1961 bei, die sich um die überfällige Neubestimmung des Verhältnisses zwi-

59 Vgl. Kittel, Die Legende, S. $16 \mathrm{f}$.

60 Heidtmann, Hat die Kirche geschwiegen?, S. 407, 402.

61 Hierzu ausführlich die Darstellung im Kapitel X.

62 So z.B. die Generalsynode der EKD im Mai 1955. Siehe Heidtmann, Hat die Kirche geschwiegen?, S. 214.

63 Heidtmann, Hat die Kirche geschwiegen?, S. 340. 
schen beiden Religionen bemühte und damit die Matrix des deutschen Protestantismus nachhaltig veränderte ${ }^{64}$.

In der vom Rat der EKD im Oktober 1965 veröffentlichten Denkschrift über „Die Lage der Vertriebenen und das Verhältnis des deutschen Volkes zu seinen östlichen Nachbarn“ wurden die „den Deutschen angetanen Unrechtstaten“ erstmals quasi kirchenamtlich begründet mit der „schwere[n] politische[n] und moralische[n] Schuld“, die das deutsche Volk gegenüber seinen Nachbarn auf sich geladen hatte, und daraus implizit der Verzicht auf die seit 1945 polnisch bzw. russisch verwalteten Ostgebiete abgeleitet ${ }^{65}$. Nach Ansicht des Osteuropahistorikers Gotthold Rhode hatten die Autoren der Denkschrift unter dem Vorsitz des Tübinger Professors Ludwig Raiser nicht hinreichend bedacht, weshalb „gerade die Vertreibung Gottes Gericht" sei, das man hinzunehmen habe, „die Teilung Deutschlands und die Mauer in Berlin aber nicht"66, doch war eben damit die spätere Entwicklung der EKD-Position zur Wiedervereinigung bereits angedeutet. Die von Rhode gestellte Frage, wo eigentlich die göttliche Strafe bleibe „für die Macht, die den Überfall (auf Polen 1939, M.K.) durch den Pakt vom 23. August erst ermöglichte und dann am 17. September 1939 Polen ... überfiel und überhaupt im Bündnis mit dem Nationalsozialismus eine Politik betrieb, die in nichts moralischer war als die ihres Partners" 67 , hielt man in den Kirchenleitungen des deutschen Protestantismus seit Mitte der 1960er Jahre immer weniger für bedenkenswert, sondern setzte deutschland- und ostpolitisch auf das von Egon Bahr vor der Evangelischen Akademie Tutzing 1963 vorgestellte Projekt eines (inter-)nationalen „Wandels durch Annäherung“. In welchem gesamtgesellschaftlichen Kontext die Ostdenkschrift stand, zeigt der Blick auf die einige Jahre später von der konzeptionellen in die operative Phase übergehende "neue Ostpolitik“, die in den Verträgen von Moskau, Warschau, Prag und im Grundlagenvertrag mit der DDR den Status quo faktisch anerkannte.

Ohne das Bewußtsein von der historischen Schuld des deutschen Volkes, an dessen verstärkter Ausprägung die Evangelische Kirche in den 1960er Jahren nicht unerheblichen Anteil hatte ${ }^{68}$, wäre die sozialliberale Ostpolitik schwerlich zu verstehen. Und auch die Geste des deutschen Bundeskanzlers Willy Brandt, der den Opfern des Warschauer Ghettos durch seinen histori-

64 Nowak, Vergangenheit und Schuld, S. 123.

65 Die Lage der Vertriebenen und das Verhältnis des deutschen Volkes zu seinen östlichen Nachbarn. Eine evangelische Denkschrift, S. 7 (Zitat), S. 42 ff. Zur Entstehung der Denkschrift und ihrer Diskussion siehe v.a. das zweite und dritte Kapitel in Rudolph, Evangelische Kirche und Vertricbene.

66 Rhode, Brief an Bischof Lilje, S. 28.

67 Ebd., S. 27.

68 Und nicht nur in den 1960 er Jahren, sondern darüber hinaus von 1945 bis 1989, so betont Kurt Nowak, sei der deutsche Protestantismus „zum Platzhalter und Sprecher deutscher Schuld geworden". Nowak, Vergangenheit und Schuld, S. 120. 
schen Kniefall am Mahnmal Respekt bezeugte, konnte ihre Wirkung auf die eigenen Landsleute wohl nur in einer westlichen, protestantisch geprägten Erinnerungslandschaft voll entfalten. Vergleicht man diese mit den shintôistischen Formen des Totengedenkens in Japan, so findet sich - zumindest, wenn man die Spezifika der katholischen Position außer Betracht läßt - die von Ruth Benedict vorgenommene Unterscheidung zwischen westlicher Schuld- und fernöstlicher Schamkultur im Grundansatz bestätigt. Differenzierungen sind aber in zweierlei Richtung vorzunehmen:

So waren in Japan individuelle Verhaltensweisen zu beobachten, die nicht einfach auf den Nenner shintôistisch inspirierter Schamverweigerung zu bringen sind. Ausgerechnet ein Matsui Iwane, der nach dem Tokioter Prozeß wegen seiner Verantwortung für das Massaker von Nanking hingerichtete Oberbefehlshaber der japanischen China-Armee, hatte vor dem Richterspruch als Sühne für das Verbrechen auf einem Hügel in seiner Heimatstadt Atami einen Schrein errichten lassen. Dafür wurde Lehm von den Ufern des Yangtsekiang mit japanischer Erde vermischt und zu einer Statue der buddhistischen Göttin der Gnade geformt und gebrannt. Die Familie Matsuis stellte eigens eine Priesterin an, die vor dieser Statue für die chinesischen Opfer beten sollte ${ }^{69}$. Die Geste bleibt auch dann bemerkenswert, wenn sie vor allem darauf abzielte, die Tokioter Richter gnädig zu stimmen. Denn sie zeigt, daß im Rahmen des japanischen Synkretismus auch buddhistische Traditionen für die „Vergangenheitsbewältigung“ von Bedeutung waren; sie könnte aber zugleich auch als Ausdruck der optimistischen Weltsicht des Shintô gedeutet werden, wonach Sünde kein in der Gesinnung wurzelndes Übel, sondern etwas Äußerliches ist, „das wieder abgewaschen werden kann". 70

Auf der anderen Seite wurde gerade im christlichen Abendland bis ins 20. Jahrhundert hinein eine - in der griechisch-römischen Antike wurzelnde - Kultur der Amnestie (griechisch: „Nicht-Erinnern“) gepflegt, d.h. eine kollektive Verpflichtung, nach Kriegen oder Bürgerkriegen an Verbrechen und Massaker, unabhängig von ihrem Ausmaß, nicht mehr zu erinnern. Im Edikt von Nantes (1598) verordnete Heinrich IV. expressis verbis, die Erinnerung an das Geschehene solle „ausgelöscht und eingeschläfert“ sein, und beim Westfälischen Friedensschluß 1648 hieß es, „beiderseits soll das ewig vergessen und vergeben, alle Beleidigungen, Gewalttätigkeiten, Schäden und Untaten derart gänzlich abgetan sein, daß alles in ewiger Vergessenheit begraben sei“" 71 . Erst im Zeitalter des Nationalismus und der Weltkriege des 20. Jahrhunderts sollte sich diese Haltung grundlegend ändern. Nachdem quasireligiöse totalitäre Ideologien teilweise mittels moderner Technologie

69 Chang, Die Vergewaltigung von Nanking, S. 185.

70 Lokowandt, Shintô, S. 32, 69 (Zitat).

71 Meier, Erinnern - Verdrängen - Vergessen, S. $937 \mathrm{ff}$. 
und Bürokratie Massenverbrechen von monströser Dimension politisch organisiert hatten, wurde mit der Jahrtausende alten Tradition des NichtErinnerns gebrochen und das an sich archaische Gesetz des „Niemals vergessen!“ wie eine Art elftes Gebot als „moralische Verpflichtung wieder in Geltung gesetzt" 72 .

Wie fremd der protestantisch geprägte Prozeß der „Vergangenheitsbewältigung“, als „(inneres) Verarbeiten der Vergangenheit“ (Duden, 2. Aufl. 1989) und aufgeklärter Umgang mit der problematischen eigenen Geschichte in der NS-Zeit verstanden, sich in einer shintôistischen Kultur ausnähme, zeigte sich schlaglichtartig im Juli 1992. Damals wurde das Wort „Vergangenheitsbewältigung“ in der japanischen Öffentlichkeit - in einer Leitartikelserie der Zeitung Asabi zum Thema „Wiedergutmachung“ - erstmals vor einem Millionenpublikum präsentiert und mit „Vergangenheitsüberwindung “ rückübersetzt. Denn die Vorstellung, daß an Vergangenem irgend etwas aktiv und „innerlich“ zu bewältigen wäre, käme dem Durchschnittsjapaner sehr fremd vor. Für ihn überwindet sich Vergangenheit „gewissermaßen selbst, indem sie Tag für Tag in weitere Ferne rückt und von der um sich greifenden Gegenwart bzw. wachsenden Vergangenheitsschichten verdrängt wird."73. Schon die schiere „faktische Präsenz der Nachkriegszeit" bewies in shintôistisch-konfuzianischem Verständnis von Vergangenheit mithin „die vollständige Überwindung der Vorkriegszeit"74.

\section{Geschichtspolitik}

Merkmale einer shintôistischen Erinnerungslandschaft wies seit Mitte der 1950er Jahre auch das japanische Bildungssystem auf. Wichtige Reformen der unmittelbaren Nachkriegszeit wurden nun wieder rückgängig gemacht. Damals, im September 1945, hatte das japanische Erziehungsministerium selbst in vorauseilendem Gehorsam das Überpinseln militaristischer und ultranationalistischer Textstellen in den Schulbüchern angeordnet, und die amerikanische Besatzungsregierung hatte in der Shintô-Direktive vom Dezember des Jahres obendrein die Vermittlung shintôistischer Lehrinhalte sowie den schulischen Besuch von Schreinen untersagt. Auch das ominöse Kaiserliche Erziehungsedikt von 1890 wurde im Juni 1948 - mit Zustimmung des Parlamentes - per Erlaß der Militärbehörden abgeschafft. Die neuen Bücher verzichteten künftig auf religiöse Doktrinen und vor allem auch darauf, uralte japanische Mythen von alten Göttern und ihren kaiserlichen Nachkommen den Schülern als Realgeschichte zu präsentieren. Aller-

72 So der Wiener Philosoph Rudolf Burger, Die Irrtümer der Gedenkpolitik, S. 13.

73 Hijiya-Kirschnereit, „Kriegsschuld, Nachkriegsschuld“. S. 327.

74 Gluck, Das Ende der „Nachkriegszeit“, S. 63. 
dings war die Durchsetzung des Rationalitätsprinzips den US-Behörden nur gegen zähen Widerstand japanischer Stellen gelungen, die sich immer wieder hinter dem "tremendous problem of translation and typing“ und daraus resultierenden Mißverständnissen verschanzten ${ }^{75}$. Bald nach dem Abzug der Amerikaner begannen sie mit einem erziehungspolitischen roll back. Die sogenannten „Abweichungen“, denen die administrativ verordnete Umorientierung des Geschichtsunterrichts seit 1953 den Kampf ansagte, meinten Darstellungen von Fakten, „die der Ausbildung von Vaterlandsliebe im Wege standen und eine positive Einstellung zum Aufbau der Selbstverteidigungsstreitkräfte nicht förderten, natürlich auch Versuche einer offenen Vergangenheitsbewältigung" "76.

Ein von Ienaga 1952 verfaßtes und weit verbreitetes Lehrbuch für den Geschichtsunterricht an Oberschulen galt dem Erziehungsministerium vier Jahre später als „einseitig“, d.h. zu kritisch hinsichtlich der japanischen Kriegführung in China. Der Historiker und damalige Gymnasiallehrer, in den Nachkriegsjahren von einem amerikakritischen Nationalkonservativen zum linken Sozialhistoriker mutiert, wurde aufgefordert, Passagen über das Nankingmassaker, Vergewaltigungen durch japanische Soldaten und die Menschenversuche in der Mandschurei zu streichen. Als seine wiederholten Versuche, dem Ministerium entgegenzukommen und das Buch umzuschreiben, der Behörde nicht weit genug gingen, zog der sich gedemütigt fühlende Ienaga 1965 vor Gericht, wo sich das Verfahren bis in die 1990er Jahre durch mehrere Instanzen zog77. Das Ministerium warf der Darstellung Ienagas vor, die Unterrichtsziele im Fach japanische Geschichte zu verfehlen, „wonach durch die Beschäftigung [mit der japanischen Geschichte] die Verdienste der Vorfahren anerkannt, das Bewußtsein als Japaner vertieft und eine starke Liebe zur Nation erweckt werden soll."78 In der Folge dieser Politik verschwanden dunkle Kapitel wie das Massaker von Nanking von Mitte der 1950 er bis in die 1970er Jahre hinein komplett aus den Schulbüchern ${ }^{79}$.

Für den Prozeß der japanischen „Vergangenheitsbewältigung“ höchst aufschlußreich ist die Entwicklung auch deshalb, weil im Schulbuch-Prüfungsamt des Erziehungsministeriums eine Reihe von Historikern untergekommen waren, die vor 1945 innerhalb des Faches zur nationalistischen Richtung um Hiraizumi Kiyoshi gehört und eine japanistische Geschichts-

75 Zit. nach Rosenzweig, Erziehung, S. 133.

76 Vorwort von Manfred Hubricht in: Inoue, Geschichte Japans, S. 9.

$77 \mathrm{Zu}$ den Ienaga-Prozessen Conrad, Auf der Suche, S. 209 f., Buruma, Erbschaft, S. 240-251, sowie Hicks, Japan's War Memories, S. 111-122, dort auch eine weiterführende Entstehungsgeschichte des "textbook screening“(S. 100-110).

78 Zit. nach Foljanti-Jost, Schulbuchgestaltung als Systemstabilisierung, S. 40.

79 Yoshida, A Battle over history, S. 76. Zu den Aktivitäten einer „Forschungsgruppe für ein freiheitliches Geschichtsbild“ in Japan seit Mitte der 1990er Jahre Igari, Die Schulbuchkontroverse, S. 270-280. 
auffassung vertreten hatten ${ }^{80}$. Ausgerechnet die im Rahmen des purge von den großen Universitäten vertriebenen Hiraizumi-Schüler dominierten also schon bald nach dem Friedensvertrag von San Francisco wieder die Geschichtspolitik der Regierung. Dies wurde ihnen freilich dadurch erleichtert, daß sich in der universitären Historikerschaft nach 1945 in „historiographischer Koalition" 81 mit den Alliierten die Marxisten durchgesetzt hatten. Gegen die Hervorbringungen einer weniger extremen, eher (links-)liberalen oder liberal-konservativen "Zunft" hätten sich die japanisch-nationalen Regierungsbeamten während der 1950er Jahre in der öffentlichen Meinung vermutlich weniger leicht mit Hilfe des antikommunistischen Zeitgeistes - und der Elternschaft - behaupten können, zumal auch die Lehrer in ihrer Mehrheit durchaus links-kritisch eingestellt waren ${ }^{82}$. Hinzu kam, daß die marxistischen Historiker die Kapitulation Japans vielfach nicht als eigenes Scheitern wahrnahmen, sondern als Bestätigung ihres politischen Standpunktes. Das Tennô-System mit Militär, Bürokratie, Monopolkapital und Großgrundbesitz wurde demnach zum hauptsächlichen Gegenstand ihrer stark binnenorientierten Kriegschulddebatte; und diese rein objektiv angelegte Erörterung der Kriegsschuld ließ „keinen Raum für die Klärung der subjektiven Verantwortung eines jeden Individuums" 83 . Über japanische Kriegsverbrechen aufzuklären und die Opfererfahrungen asiatischer Nachbarländer zu berücksichtigen, fühlte sich auch die marxistische Geschichtswissenschaft nicht recht zuständig.

Statt dessen wurde spätestens seit Mitte der 1950er Jahre gesamtgesellschaftlich ein "revisionistisches" affirmatives Geschichtsbild prägend. Brandmarkte die marxistische Schule den Krieg zumindest als imperialistische Aggression gegen das unschuldige chinesische Volk, so hielt der ehemalige Obrist Hattori Takushirô in seiner 1953 veröffentlichten vierbändigen Militärgeschichte das Massaker von Nanking nicht einmal mehr der Erwähnung für bedürftig. Ebenso typisch wie für Hattori war für die Darstellung von Takeyama Michio, der 1956 eine „Geistesgeschichte der ShôwaZeit“ (also der Jahre seit der Thronbesteigung des Tennô Hirohito 1926) vorlegte, die Betonung der Schicksalhaftigkeit der historischen Entwicklung, einschließlich der Japan vom Westen aufgezwungenen Modernisierung, die gleichsam zwangsläufig nach Pearl Harbor geführt habe. Der Weltkrieg erschien dabei in erster Linie als antikolonialer Kampf gegen die USA, wobei der in der Besatzungszeit untersagte Propagandabegriff des

$80 \mathrm{Vgl}$. Conrad, Auf der Suche, S. $211 \mathrm{f}$.

81 Ebd., S. 199.

82 So bekannte sich dic Lehrergewerkschaft 1952 in einem ethischen Kodex zur „historischen Verpflichtung der Friedenssicherung" und warf der Regierung vor, einen neuen Krieg vorzubereiten. Thurston, Teachers and Politics, S. 87. Zum Verhalten von Lehrern im Klassenzimmer vgl. auch Krauss, Japanese Radicals Revisited, S. 59.

83 Fuhrt, Erzwungene Reue, S. 40. 
"Großostasiatischen Krieges“, d.h. eines Befreiungskrieges der asiatischen Völker, wieder häufig auftauchte ${ }^{84}$. Für seine zeithistorische Rolle, so der bekannteste Hiraizumi-Schüler Murao Jirô in seiner Gesamtdarstellung über „Das Leben des Volkes“ (1965), werde Japan „von den asiatischen Völkern Dank entgegengebracht" 85 . Die von ihm und anderen „revisionistischen" Historikern vertretene Auffassung, daß Geschichtsschreibung einen Beitrag zur Konstituierung der nationalen Gemeinschaft zu leisten habe und die jüngste Vergangenheit schon deshalb nicht so negativ dargestellt werden dürfe, wie dies die Marxisten unternähmen, wurde in der konservativen politischen Führung so weitgehend geteilt, daß japanisch-nationale Wissenschaftler von den Behörden auch privilegierten Quellenzugang erhielten ${ }^{86}$. Dagegen legten die zuständigen Stellen ihren großen Entscheidungsspielraum gegenüber marxistischen Historikern so ungünstig aus, daß diesen die Sichtung eventuell brisanter amtlicher Dokumente verwehrt blieb. Infolgedessen konnte man ihren Studien dann auch fast zwangsläufig einen Mangel an empirischer Basis vorwerfen ${ }^{87}$.

Demgegenüber ermöglichte es in Westdeutschland eine von Bund und Ländern betriebene liberale Wissenschaftspolitik den Historikern, die zeitgeschichtlichen Quellen ausgiebig zu nutzen. Diese lagen im Vergleich zu Japan obendrein ungleich günstiger, nicht nur weil auf der Insel vor Ankunft der Amerikaner mehr zentrale Aktenbestände etwa aus der Provenienz des Auswärtigen Dienstes vernichtet worden waren, sondern auch weil die Besatzer in Nippon bei der Sichtung und Sammlung von amtlichem Beweismaterial zur Vorbereitung der Kriegsverbrecherprozesse weniger systematisch vorgegangen waren als in Deutschland. An dessen Archive hatte man die beschlagnahmten Bestände dann bald zum Zwecke der wissenschaftlichen Auswertung zurückgegeben. In Japan dagegen wurde überhaupt erst 1971 ein öffentliches Staatsarchiv (für die Regierungsakten seit der Meiji-Zeit 1868) eingerichtet, so daß die seit Ende der 1950er Jahre aus den USA zurückkommenden Dokumente in den Registraturen der staatlichen Ressorts verschwanden und die Forschung keinen systematischen Überblick über die Bestände gewinnen konnte ${ }^{88}$.

${ }^{84}$ Conrad, Auf der Suche, S. 199f., $204 \mathrm{f}$.

85 Ebd., S. 211.

86 Dies galt etwa für den Diplomatiehistoriker Tsunoda Jun, der 1962/63 mit seiner siebenbändigen Quellenedition über den „Weg in den Pazifischen Krieg“ erstmals größere Archivbestände der Öffentlichkeit zugänglich machte; er deckte zwar die Verwicklung Tokioter Heeresstellen in die Vorbereitung des Mandschurei-Konfliktes oder auch die kriegstreibende Rolle der Marine auf, schilderte die Ereignisse aber insgesamt so, als sei Japan in den Krieg "hineingeschlittert“. Conrad, Auf der Suche, S. 200.

87 Ebd., S. $200 \mathrm{ff}$.

88 Nicht staatlich ausgebildete Archivare, sondern Beamte in Behördenarchiven bestimmten das Bild. Vgl. Broszat, Zeitgeschichte, S. 290. 
Neben diesen unterschiedlichen materiellen Ausgangsbedingungen beider Zeitgeschichtswissenschaften muß auch ein ideeller Faktor berücksichtigt werden: Die marxistisch dominierte Historikerschaft in Japan stand spätestens seit Mitte der 1950er Jahre außerhalb der konservativ geprägten Gesellschaft, und diese weite Entfernung vom nationalen Geleitzug begrenzte ihren Einfluß erheblich. Die konservative Zunft der deutschen Geschichtswissenschaftler war dagegen integraler Bestandteil der Gesellschaft der Adenauer-Zeit und eben deshalb viel wirkungsvoller. In Japan konnte sich das Geschichtsbild von Marxisten und linken „Modernisten“, denen sich die jüngere Entwicklung ihres Landes - rasches wirtschaftliches Wachstum bei vorenthaltenen politisch-sozialen Partizipationschancen - als „weltgeschichtlicher Sonderweg“ darstellte, nicht durchsetzen ${ }^{89}$. In der Bundesrepublik dagegen prägten national-konservative Professoren wie Gerhard Ritter ${ }^{90}$, der wegen seiner Haftzeit nach dem 20. Juli auch hohe moralische Autorität genoß, das historische Bewußtsein in den 1950er Jahren entscheidend mit, indem sie vor allem auch - gegen die Vorstellung von einem deutschen Sonderweg in das Dritte Reich - Bismarcks Reichsgründung als Implementation der nationalstaatlichen Bewegungsgesetze des 19. Jahrhunderts verteidigten und gleichzeitig dessen Außenpolitik scharf vom nationalsozialistischen Lebensraumwahn Hitlers abgrenzten ${ }^{91}$. Innerhalb eines derartigen, gesellschaftlich vermittelbaren historischen Erklärungszusammenhangs fand auch die politisch so wichtige Distanzierung vom untergegangenen Regime und von seinen Verbrechen viel eher Akzeptanz als dies in Japan auf der theoretischen Basis des Sonderwegs möglich war. Ja, die anfangs dominierende Konzentration auf die normative Distanzierung vom Nationalsozialismus selbst, statt auf wirkliche oder vorgebliche Strukturfehler der deutschen Modernisierung, hat nolens volens wohl erst die Grundlagen dafür geschaffen, daß in den 1960er Jahren dann auch in der Historikerzunft der Bundesrepublik - allerdings mit sehr viel mehr gesamtgesellschaftlichem Nachdruck - über den nationalen Sonderweg und den - wie Fritz Fischer meinte - wiederholten deutschen „Griff nach der Weltmacht" diskutiert werden konnte. Das Sträuben vieler Historiker in der Adenauer-Zeit, sich der Geschichte der NS-Massenverbrechen „direkt und ungeschützt zu stellen“, ihre „halben Zugeständnisse“ und „verzweifelten Traditionsrettungen“ waren - so hat es Nikolas Berg beschrieben - „nicht das Gegenteil eines Nachdenkens über den Nationalsozialismus ..., sondern das Medium, in welchem es stattfinden konnte."92

89 Conrad, Auf der Suche, S. 405.

$90 \mathrm{Vgl}$. Cornelißen, Gerhard Ritter.

91 Conrad, Auf der Suche, S. 65.

92 Berg, Lesarten des Judenmords, S. 138. Andere Einsichten Bergs, der den Beitrag zur Erklärung des Holocaust zum alleinigen Maßstab macht, an dem die deutschen Historiker nach 1945 zu messen seien, und dabei die erinnerungskulturelle Notwendigkeit der Erforschung 
Die unter erinnerungskulturellen Aspekten vergleichsweise günstige Entwicklung der bundesdeutschen Geschichtswissenschaft zeigte sich auch da, wo sie mit am breitesten in die Gesellschaft hineinwirkte: im Bereich der Schulbücher. Zwar war in der Bundesrepublik gerade am Anfang der 1950er Jahre ein beträchtliches Maß an didaktischer Unsicherheit gegenüber einem Zeitabschnitt festzustellen, der erst wenige Jahre zurücklag und wissenschaftlich noch kaum erforscht sein konnte. So wurde z.B. Hitlers Kriegspolitik in einem einschlägigen Geschichtsbuch zunächst nur als „verfehlt", in einer späteren Auflage erst als „verbrecherisch“ bezeichnet ${ }^{93}$, doch wurde aufs Ganze gesehen im ersten Jahrzehnt der Bundesrepublik, unterstützt von „zahlreichen Fortbildungstagungen ..., geleitet von neuen Lehrplänen, mit Hilfe von neuen Schulbüchern sowie des neuen Handbuchs von Rassow ... ein solider Geschichtsunterricht erteilt"94, der die Terrormaßnahmen des NS-Staates keineswegs verharmloste oder gar verschwieg95. Als nach der neonazistischen Schmierwelle 1959/60 die auch vorher immer wieder einmal erhobene Klage über den geringen zeitgeschichtlichen Kenntnisstand der deutschen Schüler („Hitler und Ulbricht - Fehlanzeige “96) besonders laut wurde, versicherte der international bekannte Schulbuchforscher Georg Eckert dem kulturpolitischen Ausschuß beim SPD-Parteivorstand:

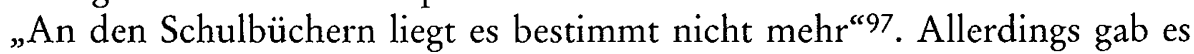
offensichtlich Lehrer, die an das Thema „Nationalsozialismus“ aus biographischen oder politischen Gründen tatsächlich nicht recht heranwollten, woraus sich später dann der Mythos von der pauschalen Verdrängung des Dritten Reiches an den Schulen der Adenauer-Zeit speiste. Restaurative Eingriffe der staatlichen Kultusbehörden, ob sie nun sozial-, christ- oder freidemokratisch regiert wurden, zwecks Ausmerzung von Schulbüchern, die offen über NS-Verbrechen unterrichteten, wären jedoch - und das ist entscheidend - in der Bundesrepublik ganz und gar unvorstellbar gewesen.

des Nationalsozialismus und seiner Strukturen unterschätzt, sind weniger nachvollziehbar; etwa auch die Kritik an Hans Rothfels, den „allgemeinen apologetischen Reflex der Deutschen nach 1945 als Wissenschaft" etabliert zu haben. Vgl. Berg, Der Holocaust und die westdeutschen Historiker, S. 163.

93 Uhe, Der Nationalsozialismus in den deutschen Schulbüchern, S. 245.

94 Kosthorst, Von der "Umerziehung" über den Geschichtsverzicht zur "Tendenzwende“, S. 138.

$95 \mathrm{Zu}$ diesem Urteil kam 1961 auch Oberstudiendirektor Karl Mielcke, der auf Anregung der Ständigen Konferenz der Kultusminister über fünfzig Lehrbücher untersucht hatte. Mielcke, 1917-1945 in den Geschichtsbüchern der Bundesrepublik, S. 68.

96 Rheinischer Merkur, 22. Mai 1959.

97 Der Vorwärts, 29. Januar 1960. 


\section{Die Rolle der Journalisten}

Die geringe Durchschlagskraft der vergangenheitskritischen Historiker im öffentlichen Diskurs Japans hing auch damit zusammen, daß es ihnen an Unterstützung aus dem weiteren intellektuellen Milieu mangelte. Ein Exodus der Kultur hatte in den Jahren des Militärregimes nicht stattgefunden, einen japanischen Thomas Mann gab es nicht. Innere Emigration war - von wenigen Kommunisten abgesehen - die höchste Form des Widerstandes unter Künstlern und Literaten geblieben. So hatten etwa Schriftsteller wie Nagai Kafû im privaten Kreis oder in ihren Tagebüchern die Vulgarität des Militarismus beklagt. Aber die allermeisten hatten sich angepaßt, nicht zuletzt viele ehemalige Linke, die in den 1930er Jahren in Form eines tenko ihren Überzeugungen abschworen. Auch wenn sie sich nach 1945 nicht selten sofort wieder dem Marxismus zuwandten, waren sie offensichtlich kaum disponiert, Beiträge zur Bewältigung der Vergangenheit zu leisten oder auch nur einzufordern ${ }^{98}$.

Mehr noch galt dies für die japanischen Journalisten, die oft bis $1945 \mathrm{dem}$ zunehmenden Ultranationalismus das Wort geredet und publizistisch für die "Großostasiatische Wohlstandssphäre" agitiert hatten. So hatten die herrschenden Militärs bezeichnenderweise keine einzige Zeitung verbieten müssen. Denn die meist von Samurai gegründeten Blätter waren schon vor der Machtübernahme des Militarismus traditionell in engstem Verhältnis zur nationalen Obrigkeit gestanden. Die Bereitschaft, sachliche Berichterstattung und kritische Kommentierung aufzugeben, um die Informationskanäle zur Macht nicht zu verlieren, war ebenso weit verbreitet wie der am Ende des 19. Jahrhunderts sich endgültig verfestigende „Geist des Ausgleichs und der Mäßigung um (fast) jeden Preis“.99

Zwar hatten die US-Besatzer geplant, die Zeitungslandschaft grundlegend zu verändern, doch die allgemeine wirtschaftlich-soziale Lage, Papierknappheit, mangelhafte Produktionsanlagen und Fachkräftemangel hatten die Neugründung von Zeitungen gehemmt. Gewiß hatten die bald nach Kriegsende entstandenen Betriebsgewerkschaften die Führung der drei größten Zeitungen zum Rücktritt gezwungen. Und im Rahmen des purge wurden immerhin die Aktivitäten mutmaßlicher Ultranationalisten zwischen 1937 und 1941 (wenn auch nicht bis 1945!) überprüft ${ }^{100}$. Doch traten nach Aufhebung der alliierten Vorzensur (1948) und dem Ende der Berufsverbote die 1945/46 „hinweggesäuberten“ Zeitungsleute wieder in Erscheinung. Auf der Basis der institutionellen und personellen Kontinuitäten kam es zu einer Fortsetzung japanisch-nationaler Traditionen im Journalis-

98 Vgl. Buruma, Erbschaft, S. 84, sowie Iwabuchi, Die Vergangenheitsbewältigung.

99 M. Pohl, Presse und Politik in Japan, S. 11 ff., Zitat. S. 14.

100 Vgl. Baerwald, The Purge, S. $37 \mathrm{f}$. 
mus ${ }^{101}$; zumal nicht nur die kommunistisch gesinnten Journalisten, die in vielen Redaktionen kurzzeitig das Ruder übernommen hatten, bereits Ende der 1940er Jahre im Zuge der zweiten, „roten“ Säuberungswelle wieder entfernt worden waren, sondern mit ihnen auch manche Liberale, die nur im Verdacht kommunistischer Überzeugungen standen.

Ihrem Selbstverständnis nach neigten die japanischen Journalisten weiterhin dazu, ihre Arbeit der nationalen Räson unterzuordnen und gerade erinnerungskulturelle Tabus hinsichtlich der Rolle des Tennô im Krieg oder der Beziehungen zu Korea zu beachten. Trotz uneingeschränkter Pressefreiheit gab es im Journalistenstand also mentale Hemmungen, einer womöglich nicht regierungskonformen „heißen Story“ nachzujagen, zumal dann, wenn man bei einem Thema die Bevölkerungsmehrheit nicht hinter sich wissen konnte. Zur „Vierten Gewalt“ wurde die japanische Presse nicht aufgrund ihrer demokratischen Wächterfunktion, sondern als Teil des politischen Establishments, mit dem sie nach wie vor eng verknüpft ist ${ }^{102}$. Daß die bekannten "großen fünf“103 Tageszeitungen des Landes sich bei zentralen politischen Fragen oft wie in einem „anonymen Konsensus"104 verbunden zeigten, verwundert nicht, wenn man bedenkt, wie sehr alle führenden Blätter - mit der einzigen Ausnahme der kommunistischen Akabata (Rote Fahne) - „von der konservativen Politik und ihren Teilinteressen gesteuert“ waren ${ }^{105}$.

Häufig auch wechselten Journalisten unter diesen Auspizien ganz in die Politik und bestätigten damit im Umkehrschluß die alte Empfehlung des Tokyo Nichi-nichi Shimbun-Herausgebers: „Wenn man nicht Ministerpräsident werden kann, sollte man Journalist werden!"106 Vor allem die Fraktion der Konservativen wies traditionell einen auffallend hohen Anteil an Zeitungsleuten auf, darunter auch viele oya-bun („Bosse“), d.h. Vertrauensleute der Wirtschaft, der Ministerialbürokratie oder der parlamentarischen Ausschußvorsitzenden ${ }^{107}$. Exemplarisch genannt sei Ogata Taketora, der seine journalistische Karriere bei der bedeutenden Asabi begonnen hatte, während des Krieges 1944 bis zum Staatsminister und Chef des Informationsamtes avancierte, dafür in den Jahren 1946 bis 1951 auch mit Berufsverbot belegt war, aber 1952 unmittelbar nach seiner Wahl in das Unterhaus erneut Staatsminister und Kabinettssprecher wurde und als führendes Mitglied der konservativen Regierungspartei schließlich sogar als aussichtsrei-

101 M. Pohl, Presse und Politik in Japan, S. 22.

102 Ebd., S. $29 \mathrm{ff} ., 38 \mathrm{ff}$., $50 \mathrm{f}$.

103 Wagner, Massenmedien, in: Pohl/Mayer, Länderbericht Japan, S. 455-460, hier S. 456.

104 M. Pohl, Presse und Politik, S. 51.

105 So Zahl, Die politische Elite Japans, S. 179, im Blick auf die 1950er und 1960er Jahre.

106 Zit. nach M. Pohl, Presse und Politik, S. 16.

107 Zahl, Die politische Elite Japans, S. 114. 
cher Kandidat für das Amt des Premierministers galt, ehe er im Alter von 68 Jahren Anfang 1956 überraschend verstarb ${ }^{108}$.

In der Bundesrepublik Deutschland wären derartige Karrieren dagegen kaum denkbar gewesen, da die Reform des Mediensystems in den westlichen Zonen viel weiter gegangen war als in Japan. 1945 wurden alle bestehenden Zeitungen von den Besatzungsmächten aufgelöst, auch die vom NSStaat verbotenen durften nicht einfach wiedererscheinen, sondern bedurften so wie alle neuen Blätter einer Lizenz, die von den Besatzungsbehörden nur an politisch nicht Vorbelastete als Herausgeber vergeben wurden ${ }^{109}$. Welche Folgen dies haben konnte, mag aus dem Beispiel Bayerns erhellen, das bei Landtagswahlen 1946 seine Verbundenheit mit der neugegründeten christlich-konservativen CSU bereits dokumentiert hatte, wo sich unter den Lizenzträgern aber noch Ende 1948 mehr Sozialdemokraten als ChristlichSoziale befanden. Und als die Altverleger mit der "Generallizenz" im Juni 1949 wieder die Möglichkeit erhielten, in das publizistische Geschehen einzugreifen, konnten sie den sachtechnischen und wirtschaftlichen Vorsprung der neuen Zeitungen in aller Regel nicht wieder einholen ${ }^{110}$. Der von den Alliierten verordnete tiefgreifende Wandel der deutschen Medienlandschaft betraf aber auch die Chefredakteurspositionen, die nun durchgängig mit Journalisten besetzt wurden, die dem Dritten Reich distanziert gegenübergestanden hatten. Zwar tauchten in den 1950er Jahren wieder Publizisten wie Henri Nannen oder Werner Höfer auf, die einst mit der Feder ihren Beitrag zum „Endsieg“ geleistet hatten, aber sie gelangten bei der wichtigen überregionalen Presse oder gar beim Rundfunk „meist nur noch dann in einflußreiche Positionen, wenn sie sichtbare Zeichen von Sinneswandel erkennen ließen"111; ja etliche unter ihnen haben die Austilgung des Nationalsozialismus offensichtlich mit besonderem Nachdruck betrieben, um Fragen nach ihrer belastenden Tätigkeit im Dritten Reich gar nicht erst aufkommen zu lassen. Das bedeutete indes auch, daß sie die unrühmliche Vergangenheit des eigenen Berufsstandes lieber nicht zum Thema machten.

Gerade beim lautstarken Spiegel-Journalismus fiel der „doppelte Standard im Umgang mit der eigenen Geschichte und der Verwendung vergangen-

108 Vgl. M. Pohl, Presse und Politik, S. 13; Zahl, Die politische Elite Japans, S. 399. Vertiefend die Studie von Gäthke, Ogata Taketora - Journalist und Politiker. Weitere „Bosse“ journalistischer Provenienz waren z. B. Miki Bukichi, 1946-1951 mit Berufsverbot belegt, nach seinem politischen Comeback eine der wichtigsten Antriebskräfte für die Gründung einer konservativen Einheitspartei 1955, oder Kôno Ichirô, Berufsverbot ebenfalls zwischen 1946 und 1951, aber 1954 bereits wieder Minister für Landwirtschaft und Forsten. Vgl. Zahl, Die politische Elite Japans, S. 114, $363 \mathrm{f}$., $346 \mathrm{f}$.

109 Plitsch-Kußmaul, Die Entstehung und Ausprägung der Mediensysteme, S. 74, 325.

110 Koszyk, Pressepolitik für Deutsche, S. 472 f.; Weiß, Journalisten, S. 252 f.;

111 Schwarz, Die Ära Adenauer, S. 411. Eine andere Position, stärker an personellen Kontinuitäten als an den Inhalten journalistischer Arbeit orientiert, vertritt Hodenberg, Die Journalisten, v.a. S. $286 \mathrm{ff}$. 
heitspolitischer Argumente gegenüber Dritten auf“112. Besonders pikant wirkte es, wenn das Hamburger Nachrichtenmagazin die Wiedervereinigungspolitik des „rheinischen Separatisten“ Adenauer von rechts her kritisierte, weil der die Freiheit der Bundesrepublik nicht für die Einheit Deutschlands aufs Spiel setzen wollte. Denn dies warf zumindest die Frage auf, ob die „SS-Offiziere in leitender Funktion“ sowie ein weiteres „gutes Dutzend Redakteure und Mitarbeiter mit eindeutiger NS-Zuordnung "113, die unter dem nationalliberalen Herausgeber Rudolf Augstein arbeiteten, die Größe Deutschlands nach wie vor für wichtiger nahmen als den Wert der Demokratie. Dennoch ist aufs Ganze gesehen zu konstatieren, daß die publizistische Elite der Nation, schon lange bevor der Spiegel ab 1962 zum „Sturmgeschütz der Demokratie“ avancierte, unzweifelhaft „nützliche Orientierungshilfen " 114 bei der Dekontaminierung von der nationalsozialistischen Weltanschauung und der Aufklärung über die NS-Verbrechen geliefert hat. Ein Sachverhalt, der im Vergleich mit den wesentlich bescheideneren Beiträgen der japanischen Medien zur nationalen Erinnerungskultur besonders ins Auge springt und der nachdrücklich auf die Bedeutung der besatzungspolitischen Weichenstellungen für die relativ intensive „Vergangenheitsbewältigung “ in der Bundesrepublik verweist.

\section{Schlüsselfunktion des (regierenden) \\ Konservativismus bei der „Vergangenheitsbewältigung“}

Die Dichte des konservativen ,journalistisch-politischen Komplexes“ trug maßgeblich zu der von 1955 bis in die frühen 1990er Jahre dauernden Alleinherrschaft der „Liberaldemokratischen Partei“ bei - und bereits vorher zur führenden Rolle ihrer Vorgängerorganisationen. Beide Phänomene bieten einen Hauptschlüssel zum Verständnis der japanischen Erinnerungskultur, deren wesentliches Kennzeichen die letztlich nur halbherzige Wandlung des nationalen Konservativismus ist. Gerade damit aber entsprach er dem mentalen Mainstream der japanischen Nachkriegsgesellschaft am deutlichsten und vermochte er die politische Kultur des Landes von seinen Bastionen in Regierung, Parlament, Wirtschaft und Medien aus entscheidend zu formen. An der symbolischen Gründerfigur des japanischen Nachkriegskonservativismus, Yoshida Shigeru, läßt sich dies zeigen.

Der 1906 bis 1939 in langen Jahren an Botschaften in Europa, Amerika und China politisch sozialisierte Diplomat, dessen Familie sich schon zu Beginn der Meiji-Zcit zur bürgerlichen Freiheitsbewegung und zum Frei-

112 Hachmeister, Ein deutsches Nachrichtenmagazin, S. 118.

113 Ebd., S. 90 f., 98 (Zitat).

114 Graml, Die verdrängte Auseinandersetzung mit der NS-Vergangenheit, S. 172. 
handel bekannt hatte, war ein Exponent der anglophilen Richtung der japanischen Außenpolitik, überzeugt davon, daß sich sein Land auf dem chinesischen Festland nur würde behaupten können, wenn es auf einseitiges militärisches Vorgehen verzichtete und sich in der Konkurrenz mit westlichen Großmächten an internationale Spielregeln hielt. Wegen seiner prowestlichen Haltung und seines Engagements für Japans Verbleib im Völkerbund geriet Yoshida in den 1930er Jahren mehr und mehr in einen Gegensatz zur Generalität, was 1939 zu seiner Entlassung aus dem Diplomatischen Dienst führte und ihm kurz vor Kriegsende wegen Beteiligung an geheimen Friedensverhandlungen die Verhaftung durch die kempeitai einbrachte. In den Augen der Besatzungsmacht qualifizierte ihn aber gerade diese Vergangenheit auch zum Architekten einer neuen japanischen Außenpolitik. Zunächst als Außenminister, von 1946 bis 1954 dann (mit kurzer Unterbrechung 1947/48) als Ministerpräsident wies er die neutralistischen Konzepte der politischen Linken zurück und machte die Freundschaft mit den Vereinigten Staaten zum Fundament japanischer Außenpolitik ${ }^{115}$.

So positiv man Yoshidas pragmatische Diplomatie im Dienste wohlverstandener Wirtschafts- und Sicherheitsinteressen seines Landes auch einschätzen kann, so wichtig seine Kontrollfunktion an der Spitze eines staatlichen Verwaltungsapparates auch war, in dem vielfach noch altes Denken herrschte, so klar ist doch auch zu sehen, daß die „Westernisierung“ japanischer Außenpolitik von keiner ebenso tiefgreifenden „Vergangenheitsbewältigung" im Inneren begleitet wurde - nicht zuletzt weil Yoshida selbst die von den Besatzungsbehörden im Kampf gegen den Ultranationalismus ergriffenen Säuberungsmaßnahmen für überzogen hielt und kaum etwas unversucht ließ, um sie von seiner einflußreichen Position aus - auch bereits vor 1952 - wieder rückgängig zu machen. Aus Rachebedürfnis, so stellte sich der purge in Yoshidas Augen dar, hätte die Besatzungsmacht „Bereinigungen" in einem Ausmaß durchgeführt, "wie man es wohl kaum in einem anderen Land, von den kommunistisch beherrschten abgesehen, vorfindet."116 Den Vergleich mit Deutschland ließ er nicht gelten, da Japan kein totalitäres Regime gewesen sei und die Militaristen „nur für vorübergehende Zeit $[\ldots]$ in unserem Lande das Heft in der Hand gehabt" hätten. ${ }^{117}$ Anders als bei der „Nazi-Partei“ in Deutschland seien etwa die Mitglieder der Gesellschaft zur Förderung der Kaiserlichen Herrschaft, so sie Bürgermeister waren, auch automatisch Führer von Ortsgruppen gewesen. Diese "gemäßigten und zuverlässigen Elemente des Landes" würden durch die Säuberungsaktion künftig von jeder öffentlichen Tätigkeit abgeschreckt ${ }^{118}$. Immerhin durfte sich Yoshida aber etwas darauf zugute halten, das Ausmaß

115 Zahl, Die politische Elite Japans, S. 139-142, 468 f.

116 Yoshida, Japan im Wiederaufstieg, S. 144.

117 Ebd.

118 Ebd., S. 149. 
der Aktion im Presse- und Verlagswesen "auf ein zumutbares Mindestmaß“ reduziert und durch einen bewußten Übersetzungsfehler nicht, wie von der Besatzungsbehörde gefordert, sämtliche Direktoren ausgeschaltet zu haben, sondern lediglich die Generaldirektoren. Die 1947, 1949 und 1951 eingesetzten „Berufungsämter“, so betont Yoshida in seinen Erinnerungen stolz, hätten zudem sukzessive 10000, 177000 und 9000 der über 200000 gesäuberten Personen rehabilitiert, und 1952 seien schließlich sämtliche Säuberungsgesetze aufgehoben worden, darunter auch so „merkwürdige“, vom General Headquarter durchgesetzte Anordnungen wie das gegen die Ausgeschalteten gerichtete Verbot, sich politisch zu betätigen sowie Einfluß auf Führungspersönlichkeiten zu nehmen ${ }^{119}$.

Die Wiederkehr der „Ehemaligen“ wurde vor dem Hintergrund dieser konservativen Haltung zur „Vergangenheitsbewältigung“ ab 1952 zu einem ubiquitären Phänomen. Hatte sich bei den ersten Nachkriegswahlen im April 1946 der „Sprung von der Oligarchie der Thronberater zum Parlamentarismus" 120 auch darin manifestiert, daß es - nicht zuletzt infolge von Berufsverboten gegen „ältere Jahrgänge“ - einen merklichen Verjüngungsschub zu Gunsten von Abgeordneten aus Kreisen des Mittelstandes gab und $80 \%$ der Gewählten junge, politisch unerfahrene Neulinge waren ${ }^{121}$, so nahm der (1946 bei zwei bis drei Prozent liegende) Anteil konservativer Politiker aus der Beamtenlaufbahn im Unterhaus bis 1955 um das Zehnfache zu. Bei der ersten Parlamentswahl nach dem Ende der Besatzungszeit 1952 konnten sich die vorher als Militaristen und Nationalisten gesäuberten Politiker in $42 \%$ der Fälle gegen unbelastete Konkurrenten durchsetzen. Die Erfolgsquote dokumentierte, daß der Status als „Gesäuberter“ kein großes Manko bedeutete, weil es den Wählern offensichtlich entscheidend auf politische Erfahrung ankam, die am ehesten eine wirkungsvolle Durchsetzung der eigenen Klientelinteressen versprach ${ }^{122}$. Bereits vorher hatten Meinungsumfragen belegt, wie weit verbreitet die Ansicht war, die „Entmilitarisierten“ sollten nach dem Ende der Restriktionen wiederkehren und ihre weniger qualifizierten Nachfolger ersetzen ${ }^{123}$.

Tatsächlich war es gesäuberten Honoratioren auch im kommunalpolitischen Bereich teilweise gelungen, unbelastete, aber willfährige „Ersatzkandidaten" in ihre Positionen zu heben. Baerwald hat dies etwa für das Dorf Shima aufgezeigt, wo der gesäuberte Vorsitzende der Kaiserlichen Hilfsgesellschaft einen allgemein als seine „Puppe“ wahrgenommenen Nachfolger als Bürgermeister durchsetzte. Viele Gemeinden vermochten selbst derart milde Konsequenzen aus der Säuberung zu umgehen. Aufschlußreich für

119 Ebd., S. $156 \mathrm{ff} .$, Zitat S. 153.

120 Zahl, Die politische Elite Japans, S. 107.

121 Montgomery, Forced to be Free, S. 43.

122 Ebd., S. 48-52.

123 Ebd., S. 32. 
die Atmosphäre des Schlußstrichs waren Veranstaltungen wie die in Ukawara in der Präfektur Nagano, wo der Bürgermeister die Aufhebung der Säuberungsrestriktionen öffentlich feiern und die "Gesäuberten" Reden halten ließ, in denen sie ihr Verhalten während des Krieges rechtfertigten. Die Verdienste des „gesäuberten“ Altbürgermeisters wurden jetzt sogar von denen gewürdigt, die ihn einst als "Dorf-Tôjô" kritisiert hatten. Ein ehemaliger Chef der Kaiserlichen Reservevereinigung verlieh der allgemeinen Stimmung Ausdruck: Es ist eine Ehre, zu den "Gesäuberten " zu gehören ${ }^{124}$.

Da sich die japanische Öffentlichkeit nicht einmal gegen das Comeback eines Großteils der gesäuberten politischen Führungskräfte auflehnte ${ }^{125}$, konnten Spitzenbeamte aus der Laufbahn des alten Innenministeriums, die das Kriegsende 1945 ohne jeden Karriereknick überstanden hatten, in den 1950er Jahren um so eher reihenweise auch Chefpositionen im sogenannten Verteidigungsamt, in der Obersten Polizei- oder Obersten Personalbehörde übernehmen ${ }^{126}$. Noch bemerkenswerter war nur der unaufhaltsame Aufstieg von Abgeordneten wie Hatoyama Ichiro oder Kishi Nobusuke. 1945/46 bis 1952 mit Berufsverbot belegt bzw. sogar inhaftiert, brachten es beide bis in das Amt des Ministerpräsidenten.

Hatoyama, dessen konservative „Liberale Partei“ 1946 die ersten Unterhauswahlen gewonnen hatte, war bereits damals auf dem Sprung in das Ministerpräsidentenamt gewesen. Doch traf ihn der Bannstrahl der Besatzungsbehörde, die ihn mit politischem Betätigungsverbot belegte. Hatoyama war, wie zur Begründung der Maßnahme aufgelistet wurde, nicht nur als Erziehungsminister zwischen 1931 und 1934 mitverantwortlich für die Massenentlassung und -verhaftung von Lehrern, die im Verdacht „gefährlicher Gedanken" standen, er hatte auch für eine gewerkschaftsfeindliche Politik nach nationalsozialistischem Vorbild geworben, als persönlicher Emissär des Premierministers auf einer Europa- und Amerikareise 1937 Japans expansionistische China-Politik gerechtfertigt und sich insgesamt mit einer „Politik der Welteroberung“ identifiziert ${ }^{127}$. Nach Aufhebung des Berufsverbotes 1952 stand Hatoyama rasch wieder an der Spitze einer neuen, konservativen Partei, deren Erfolge - und das in der Öffentlichkeit weit verbreitete Bewußtsein, daß ihm und anderen 1946 Unrecht getan worden sei ihm schon 1954 die Eroberung des Ministerpräsidentenamtes erlaubten. Die vorübergehend ausgeschaltete „binnenländisch-nationalistische“ Richtung des japanischen Konservativismus konnte sich damit aber auch deswegen durchsetzen, weil sich nach der sechsjährigen Regierungszeit Yoshidas die Stimmen derer gemehrt hatten, die sich außenpolitisch nicht ganz so eng an

124 Ebd., S. 151 ff., 157, 160.

125 Zahl, Die politische Elite Japans, S. 204.

126 Ebd., S. 109, $136 \mathrm{f}$.

127 Baerwald, The Purge, S. 21-24. 
die USA anlehnen und normale Beziehungen zur UdSSR aufnehmen wollten ${ }^{128}$.

Der Höhepunkt der restaurativen Entwicklungen in der politischen Führungsschicht Japans wurde schließlich 1957 erreicht, als Kishi, dessen Karriere „viele Ähnlichkeiten mit der von Albert Speer" aufwies ${ }^{129}$, zum Ministerpräsidenten avancierte. In den 30er Jahren stellvertretender Minister für Industric und Handel, während des Krieges Staatssekretär im Rüstungsministerium, war er 1945 als Kriegsverbrecher der Kategorie A eingestuft worden und hatte drei Jahre im Gefängnis verbringen müssen. Nach Aufhebung des Berufsverbotes konnte er aber seine Karriere als Leiter der Wiederaufbau-Vereinigung, ab 1955 als erster Generalsekretär der fusionierten LDP fortsetzen. Mit ihm gewannen Senioren der alten wirtschaftlichen Planungsbürokratie wieder an Einfluß, die wie Kishi maßgeblich am Aufbau der mandschurischen Industrie beteiligt gewesen waren ${ }^{130}$. Hätte ein 1960 geplanter Besuch des US-Präsidenten nicht in letzter Minute abgesagt werden müssen, weil man um seine Sicherheit fürchtete, und Eisenhower tatsächlich einem führenden Mitglied des Pearl Harbor-Kabinetts seine Aufwartung gemacht, so wäre dies wohl „eine der größten Ironien der neueren Geschichte" gewesen ${ }^{131}$.

Stärker noch als die personellen Kontinuitäten im konservativen Milieu waren die geistigen. Dies zeigte sich besonders bei Fragen, wo es um die nationale Identität des Landes ging. Selbst Yoshida, prominentester Exponent des liberalen Flügels der Konservativen und Verfechter eines demokratischaufgeklärten Tennô-Ideals, wirkte in seinem Nationalbewußtsein gänzlich unerschüttert. Aufschlußreich sind hierbei die Motive, die ihn zu jenem erziehungspolitischen roll back veranlaßten, das während seiner Amtszeit stattfand. Zwar zeigte Yoshida ein gewisses Verständnis für die reeducation nach 1945, da aus Patriotismus und Tennô-Verehrung - „vor dem Krieg ... hervorstechende Qualitäten des Japaners“ - Ultranationalismus und „Militaristenhörigkeit" geworden seien, doch wurde für ihn schon in den Jahren bis 1948 deutlich, daß „demokratische Erziehung als abstraktes Konzept“ den Verlust von Patriotismus und Ehrfurcht vor dem Kaiser nicht wettmachen konnte, daß Volksschullehrer wie Universitätsprofessoren nunmehr hilflos, „ohne festumrissenes Ziel“ und „ohne rechtes Selbstvertrauen“ unterrichteten und - zu Lasten von amerikanisch inspirierter Gemeinschaftskunde - japanische Geschichte und Geographie, wenn überhaupt, nur noch

128 Dem diente dann im Oktober 1956 Hatoyamas Moskau-Besuch. Vgl. Zahl, Die politische Elite Japans, S. 228.

129 So Buruma, Erbschaft, S. 82.

$130 \mathrm{Zu}$ ihren „reform-kapitalistischen Bestrebungen“ vgl. Zahl, Die politische Elite Japans, S. 143.

131 Hicks, Japan's War Memories, S. 22. 
in einer Art und Weise lehrten, „die das Kaiserliche Haus als eine ununterbrochene Linie von Tyrannen darstellte"132.

Am meisten erstaunte Yoshida die Tatsache, daß viele Lehrer das Singen der japanischen Nationalhymne und das Hissen der Flagge als feudalistisch ablehnten, weshalb er angesichts eines „solchen Tiefpunkts“133 im Mai 1950 den Philosophieprofessor und Universitätsrektor Amano Teiju als neuen Erziehungsminister gewann. Dieser war davon überzeugt, daß zwar vor und während des Krieges zu viel Wert auf den Staat und zu wenig auf das Individuum gelegt worden sei, daß sich danach aber alles nur noch um den einzelnen gedreht habe und das staatliche Ganze folglich nicht mehr genügend Beachtung finde. Am 3. November 1950 - vor dem Krieg war dieses Datum ein nationaler Feiertag zu Ehren von Kaiser Meiji gewesen - machte Amano deutlich, wie er sich den „Mittelweg“ zwischen beiden Extremen vorstelle. An diesem „Kulturtag“ gab er eine Erklärung für das Singen der (zutiefst monarchistischen) Nationalhymne und das Hissen der Flagge ab, das bereits vorher vom General Headquarter gebilligt worden war, und sprach sich für einen „Nationalen Verhaltenskodex“ aus. Amanos Amtsnachfolger Odate Shigeo ergriff 1954 darüber hinaus die Initiative, um sich endlich jener Lehrer zu entledigen, „die Schulzimmer dazu mißbrauchten, dort ihre extremen Ideen zu propagieren und gegen den Staat gerichtete Wühlarbeit zu leisten“. Entsprechende Gesetze wurden im Mai 1954 gegen den erbitterten Widerstand der Erziehungsgewerkschaften und der linken Parlamentsminorität verabschiedet ${ }^{134}$.

Die im Kampf um die kulturelle Hegemonie im Lande nicht gerade zimperlichen Konservativen gaben seit dieser Zeit mehr denn je den erinnerungspolitischen Ton an, zumal im Zuge der 1954 beschlossenen Wiederbewaffnung Japans auch der große amerikanische Verbündete daran interessiert sein mußte, daß Schulen und Massenmedien im Sinne der Verteidigungsbereitschaft die Liebe zum Vaterland weckten ${ }^{135}$. Wie sich nationale Identität im Zuge des stürmischen Wiederaufbaus und des Einkommensverdoppelungsplanes auch mehr und mehr mit wirtschaftlicher Stärke verband, demonstrierte spätestens die Rede des Ministerpräsidenten Ikeda Hayato anläßlich des gerade eingeführten Gedenktags an die Toten des Krieges am 15. August 1963. Die Opfer des japanischen Volkes, so Ikeda, seien nicht umsonst gewesen, der bemerkenswerten friedlichen ökonomischen Entwicklung lägen vielmehr die „Hoffnungen vieler [zugrunde], die in der festen Überzeugung vom Ruhm ihres Vaterlandes fielen"136. Im folgenden

132 Yoshida, Japan im Wiederaufstieg, S. $165 \mathrm{ff}$.

133 Ebd., S. 168.

134 Ebd., S. 168 ff., Zitat S. 170. Vgl. auch Hicks, Japan's War Memories, S. 22, sowie vor allem

Duke, Japan's Militant Teachers, S. $123 \mathrm{ff}$.

135 Vgl. Inoue, Geschichte Japans, S. 619.

136 Hicks, Japan's War Memories, S. 23. 
Jahr nahm die Regierung Ikeda konsequenterweise auch die Verleihung des Kriegsgefallenenordens wieder auf, um denjenigen, „die für das Vaterland ihr kostbares Leben opferten, von staatlicher Seite her aufrichtigen Dank abzustatten und sie für ihre zu Lebzeiten erworbenen Verdienste auszuzeichnen"137.

Unter Ikedas ebenfalls konservativem Nachfolger Satô Eisaku folgten weitere Höhepunkte geschichtspolitischer Restauration. 1965 legte der zentrale Ausschuß für Erziehungsfragen, beratendes Organ des Kultusministeriums, neue Grundlinien für die Erziehung der Jugend fest, in der Kritiker eine Neuauflage des alten kaiserlichen Dekretes von 1890 sahen, weil die Maximen von der Behauptung ausgingen, die Verehrung des Tennô sei gleichbedeutend mit der Liebe zu Japan. Der in der Meiji-Zeit eingeführte „Reichsgründungstag“ kigen-setsu, das Fest des Beginns der japanischen Zeitrechnung, also des Tages, an dem der mythische Herrscher Jimmu Amt und Würden des Tennô übernahm, wurde 1967 als „Tag des Gedenkens an die Landesgründung“ wiedereingeführt, was 1948 am Widerspruch der amerikanischen Besatzungsmacht, seit 1952 am verbissenen Widerstand der Opposition gescheitert war ${ }^{138}$. Auch die zur Rechtfertigung des Tennô-Systems des Altertums erfundenen Mythen wurden wieder in die Geschichtsbücher aufgenommen. 1968 zelebrierte man schließlich große „Feierlichkeiten zum hundertjährigen Jubiläum der Meiji-Restauration"139. Wie wenig sich unter anhaltender Dominanz der LDP bis in die 1980er Jahre hinein an der Einstellung zur jüngsten japanischen Vergangenheit änderte, läßt sich am Beispiel des Ministerpräsidenten Nakasone Yasuhiro illustrieren, der 1987 bei der Einweihung eines International Research Center for Japan Studies in Kioto die auch von ihm ausdrücklich so benannte „Geschichtsauffassung des Tokioter Militärtribunal“ ironisierte und als "Selbstzerfleischung“ zurückwies: „Der Staat ist, was er ist, ob er auch den Krieg gewonnen oder verloren hat. Die Nation ist etwas, was Glorie und Schande gleichzeitig auf sich nimmt. Der Staat und seine Untertanen müssen aber die Schande wegschütteln und sich auf den Weg nach der Glorie machen."140.

Die Geisteshaltung, die bei der Gründung des neuen Japan-Zentrums im Dienste der „Selbstbehauptung und -bestätigung der japanischen Kultur" Pate gestanden hatte, erinnerte den Philosophen Mishima Ken'ichi an die Entstehung des Germanischen Nationalmuseums über 100 Jahre früher ${ }^{141}$. Tatsächlich aber ähnelte der Umgang der japanischen Konservativen mit dem Zweiten Weltkrieg insgesamt eher der Art und Weise, wie man sich im rechtsnationalen Milieu der Weimarer Republik mit der jüngsten Vergan-

137 'Tanaka, Japans Nachkriegsverantwortung, S. 406.

138 Lokowandt, Shintô, S. 58.

139 Tanaka, Japans Nachkriegsverantwortung, S. 406, sowie Inoue, Geschichte Japans, S. 620.

140 Zit. nach Mishima, Mauer in der und gegen die Öffentlichkeit, S. 128.

141 Ebd., S. 127. 
genheit des „im Felde unbesiegten“, aber dennoch untergegangenen Kaiserreichs befaßt hatte. Als der Krieg im Sommer $1945 \mathrm{zu}$ Ende ging, hatte schließlich noch kein einziger feindlicher Soldat japanischen Mutterboden betreten. In der ohnehin ausweichend unbestimmten Sprache des Landes mußte infolgedessen nie von „Kapitulation“ gesprochen werden, sondern konnte statt dessen euphemistisch von „Beendigung der Feindseligkeiten“ die Rede sein. Die amerikanischen Besatzungstruppen erschienen in dieser Perspektive bloß als „vorgeschobene Armee“142. Der Zäsurcharakter des August 1945 wurde obendrein dadurch beeinträchtigt, daß sich zumindest der 15jährige Krieg, den Japan auf dem asiatischen Festland geführt hatte, angesichts des kommunistischen Vormarsches in China im Nachhinein rechtfertigen ließ. Die außenpolitische Konstellation im ostasiatischen Raum, wo es nach 1945 kein Land gab, an das Nippon sich hätte anlehnen können oder müssen, bestärkte bei den regierenden Konservativen eher das traditionelle Außenseiterbewußtsein und mit ihm japanisch-nationale Überzeugungen, statt diese durch die Erfahrung der Einbettung in eine internationale demokratische Wertegemeinschaft tiefgreifend zu verändern. Dieser Befund kann vor allem im Vergleich zur bundesdeutschen Entwicklung kaum stark genug hervorgehoben werden.

Für die politische Klasse in Westdeutschland bestand nach 1945 offensichtlich viel mehr Anlaß, den nationalen Sonderpfad zwischen Ost und West endlich aufzugeben und neuen Wegen zu vertrauen. Ohne Einbindung in Nordatlantische Verteidigungsgemeinschaft und Europäische Wirtschaftsgemeinschaft schien die Gefahr, ebenso dem Kommunismus anheimzufallen wie der Osten des Vaterlandes, einer Mehrheit im Parlament wie in der Gesellschaft, an ihrer Spitze den neuen „konservativen“ Volksparteien CDU und CSU, nicht mehr abwendbar. Die damit zwingend verbundene Notwendigkeit, Rücksicht auf Sensibilitäten zahlreicher westlicher Bündnispartner bezüglich der „Vergangenheitsbewältigung“ zu nehmen, die noch dazu viel ausgeprägter waren als die entsprechende Empfindlichkeit des einen - amerikanischen - Verbündeten gegenüber Japan, hat die Wandlung des deutschen Konservativismus nachhaltig befördert. Daß diese freilich - mit weit reichenden Folgen für die politisch-kulturelle „Aufarbeitung" der Vergangenheit - so viel tiefer ging als die des japanischen Pendants hatte nicht nur mit der anderen außenpolitischen Konstellation nach $1945 \mathrm{zu}$ tun, sondern auch mit einem ganz anderen Erfahrungshintergrund des deutschen Konservativismus aus den Jahren der Diktatur.

War Yoshida mit seiner zumindest partiell oppositionellen Vergangenheit eine Ausnahmeerscheinung unter den konservativen Nachkriegsführern Japans, so prägten den demokratischen Neubeginn bei CDU und CSU in der Bundesrepublik ganz überwiegend katholische und evangelische Christen, 
die mit dem Nationalsozialismus in Konflikt geraten waren, sei es schon vor 1933, sei es im Kirchenkampf, sei es in anderen Formen der Resistenz oder sogar in der offenen Aufstandsbewegung des 20. Juli. Daß Politiker wie Konrad Adenauer und Eugen Gerstenmaier, Josef Müller und Alois Hundhammer, die teils selbst im Konzentrationslager gesessen hatten oder wenigstens tagtäglich damit hatten rechnen müssen, von der Gestapo abgeholt zu werden, auch intrinsisch ganz anders motiviert waren, sich vom vergangenen Regime, von dessen Ideologien und dessen führenden Epigonen scharf abzugrenzen, liegt auf der Hand. Insofern hatte es für die normative Distanzierung von der NS-Vergangenheit auch keine negativen Folgen, daß bei der Integration von „Mitläufern" und mehr oder minder Belasteten in den staatlichen Beamtenapparat (v.a. im Bereich von Justiz, Polizei und Auswärtigem Amt) manchmal zu weit gegangen wurde. Jedenfalls kann man sich ,auch in den konservativen fünfziger Jahren ... einen Bundeskanzler Albert Speer ... nur schwerlich vorstellen "143, ja nicht einmal ein Papen, ein Hugenberg oder auch nur ein Brüning hätten bei den Unionsparteien eine Chance gehabt, wo sich die Traditionslinien des deutschen Konservativismus eben nur sehr gebrochen und historisch geläutert in einer neuen Verbindung mit christlich-sozialen, aber auch liberalen Elementen fortsetzten.

Selbst die Karriere desjenigen ehemaligen NSDAP- und späteren CDUMitglieds, das es in der Geschichte der Bundesrepublik am weitesten brachte, Kurt Georg Kiesinger, taugt nicht als Gegenbeispiel. Im Februar 1933 der Partei aus dem Gefühl heraus beigetreten, „sich dem vermeintlichen nationalen Aufbruch zur Verfügung stellen zu müssen", hatte sich der Jurist dem NS-Rechtswahrerbund unter Inkaufnahme beruflicher Nachteile nicht angeschlossen, sondern bis 1940 als Rechtsanwalt „eine zurückgezogene Nischenexistenz" geführt ${ }^{144}$. Um dem Gestellungsbefehl zu entgehen, hatte er aber dann das gleichzeitige Angebot, in die neugegründete rundfunkpolitische Abteilung des Auswärtigen Amtes einzutreten, angenommen und war dort bis zum stellvertretenden Abteilungsleiter avanciert. Auf Grund dieser Belastung trugen auch Teile der CDU so schwere Bedenken gegen den redebegabten Bundestagsabgeordneten, daß er 1950 weder als stellvertretender Parteivorsitzender akzeptiert wurde noch ein überzeugendes Ergebnis bei der Wahl zum geschäftsführenden Vorstandsmitglied erhielt. Vor allem Jakob Kaiser und seine Gefolgsleute hielten es „nicht für glücklich, wenn ein Mann in der vordersten Linie der Partei liege, der seit 1933 Pg. war" 145.

Erst nach Jahren parlamentarisch-demokratischer Bewährung hatte Kiesinger sich so viel Ansehen erworben, daß er 1956 zum stellvertretenden

143 Conrad, Auf der Suche, S. 406.

144 Kleinmann, Kurt Georg Kiesinger, S. 250.

145 Adenauer: „Es mußte alles neu gemacht werden“, S. 12. 
CDU-Vorsitzenden, 1958 zum Ministerpräsidenten von Baden-Württemberg und 1966 zum Bundeskanzler gewählt wurde. Dies hinderte lautstarke „68er" nicht, Kiesinger auf Versammlungen mit „Sieg-Heil“-Rufen und Sprechchören: „Wir wollen unseren Führer sehen“, zu begrüßen ${ }^{146}$. Auf dem Berliner Bundesparteitag der CDU 1968 wurde der Kanzler von der jungen Beate Klarsfeld, die mit Hilfe der SED eine Kampagne gegen ihn anführte, sogar geohrfeigt ${ }^{147}$. Für Kiesinger selbst war dies alles um so tragischer, als zu den wichtigsten Gründen für die Bildung einer Großen Koalition mit der SPD unter einem Vizekanzler Willy Brandt seines Erachtens der Versuch zählte, eine „Aussöhnung zwischen dem Emigranten und dem ehemaligen Parteigenossen" herbeizuführen148. Auf der anderen Seite konnte man sich aber auch fragen, ob die CDU gut beraten war, für das wichtigste Amt im Staate überhaupt jemanden zu benennen, der zu solchen Vorwürfen wegen seiner Vergangenheit Anlaß gab.

Die hohen Wellen, die der „Fall“ des Bundeskanzlers Kiesinger schlug, stehen in einem deutlichen Kontrast zu dem vergleichsweise glatten Karriereverlauf des erheblich stärker belasteten und zeitweilig als Kriegsverbrecher inhaftierten Ministerpräsidenten Kishi. Noch deutlicher werden die erinnerungskulturellen Unterschiede im Blick auf Yoshida und Adenauer, die beiden legendären Gründergestalten des japanischen bzw. bundesdeutschen Nachkriegsstaates. Zwar wollte auch Adenauer einen Schlußstrich unter die in ihrer Durchführung mißglückte Entnazifizierung setzen. Doch ist zum einen zu berücksichtigen, daß diese in den deutschen Westzonen tatsächlich ungleich durchgreifender gewesen war als in Japan; zum anderen verbanden sich bei Adenauer pragmatische Personalpolitik und intaktes, katholischruhiges Nationalgefühl eben nicht mit einer Verharmlosung dessen, was in deutschem Namen zwischen 1933 und 1945 angerichtet worden war. Wie bisher üblich die erste Strophe des Deutschlandliedes („Deutschland, Deutschland über alles!") als Nationalhymne zu singen, schien Adenauer nach dem Mißbrauch des Textes im Dritten Reich nicht möglich. Und selbst bei seinem schließlich erfolgreichen Bemühen, die inhaltlich für einen demokratischen Rechtsstaat zweifelsohne passende dritte Strophe durchzuset-

146 Kleinmann, Kurt Georg Kiesinger, S. 261.

$147 \mathrm{Vgl}$. Althoff, Kiesinger, die APO und der Nationalsozialismus, v.a. S. $216 \mathrm{ff}$., sowie den Vorbericht von Rainer Blasius über dic voraussichtlich im Herbst 2004 erscheinende Kiesinger-Biographie von Philipp Gassert in der Frankfurter Allgemeinen Zeitung, 5. Mai 2004.

148 Kroegel, Einen Anfang finden!, S. 170. Zu Emigration und Widerstand behielt Kiesinger indes zeitlebens ein sehr ambivalentes Verhältnis. Einerseits „respektierte, ja bewunderte er jene Deutschen, die aufgrund ihrer Überzeugung das Land damals verlassen hatten " und wandte sich im Bundestagswahlkampf 1961 öffentlich gegen Adenauers Formulierung „Brandt alias Frahm“, andererseits schrieb er noch in seinen Memoiren, er „hätte es nicht fertiggebracht, auf die Katastrophe für das deutsche Volk hinzuarbeiten, die aus einem Unterliegen Deutschlands in dicscm Völkerringen hervorgehen mußte ... Sabotage oder aktive Widerstandshandlungen kamen für mich nicht in Frage." Zit. nach cbd. 
zen („Einigkeit und Recht und Freiheit“), begegnete er Bedenken seitens des liberalen Bundespräsidenten und von Teilen der Sozialdemokratie ${ }^{149}$. Über Adenauers - bereits erwähntes - klares Bekenntnis zur „Wiedergutmachung" an den Juden und zur besonderen Verantwortung Deutschlands für Israel hinaus war seine gesamte Außenpolitik von der Erfahrung des Scheiterns deutscher Großmacht- und Schaukelpolitik zwischen Ost und West geprägt, was sich vor allem in dem Bemühen um eine historische Versöhnung mit Frankreich ausdrückte. Aber auch Polen gegenüber fand Adenauer etwa in seiner Rundfunkansprache zum 20. Jahrestag des Beginns des Zweiten Weltkriegs am 31. August 1959 klare Worte. Dieses „sympathische Volk“ sei, „ohne daß es irgendeine Schuld traf“, zum ersten Opfer des Krieges geworden, als die Truppen Hitler-Deutschlands und der Sowjetunion „in das Land einfielen und es grausam zerstörten“. ${ }^{150}$ Natürlich hatte diese Aussage eine antitotalitäre Stoßrichtung im Kalten Krieg gegen den Kommunismus, der damals gerade im Begriffe war, die Freiheit Westberlins zu bedrohen; historisch falsch und erinnerungskulturell kontraproduktiv war die Rede damit aber nicht, enthielt sie doch - ganz im Gegenteil - abermals eine klare regierungsamtliche Verurteilung der verbrecherischen Polen-Politik des Dritten Reiches.

Dem außenpolitischen Kurs der neuen, gemäßigt konservativen Volksparteien CDU und CSU korrespondierte ihre innenpolitische Position der Mitte; sie überließ das noch beachtliche, für nationalistische Sirenenklänge anfällige rechte Wählerspektrum der Deutschen Partei, dem Bund der Heimatvertriebenen und Entrechteten oder den Freien Demokraten, wo sich zeitweilig auch einige der verdächtigsten „Ehemaligen“ zu sammeln suchten. So wurden auf Weisung des britischen Hochkommissars Sir Ivone Kirkpatrick im Januar 1953 sechs Mitglieder des sogenannten NaumannKreises verhaftet, weil der von dem ehemaligen Staatssekretär im Reichspropagandaministerium, Werner Naumann, geleitete Zirkel systematisch versucht hatte, demokratische Parteien, vor allem FDP, DP und BHE „zu durchsetzen, um sich ihrer zu bemächtigen und so einen kalten Staatsstreich vorzubereiten"151. Empört zweifelte FDP-Bundesjustizminister Thomas Dehler zunächst daran, ob das vorliegende Material zur Anklageerhebung ausreichen würde, kam mit einigen Monaten Abstand indes zu der Überzeugung, daß die Engländer mit ihrem Eingreifen politisch „etwas Positives geschaffen“ hatten, da der Naumann-Kreis die „Keimzelle eines wiederer-

149 Als Adenauer bei einem Berlin-Besuch 1950 eine öffentliche Kundgebung im Titaniapalast mit dem Gesang der dritten Strophe des Deutschlandliedes beenden ließ, verließen einige Angehörige des SPD-Vorstandes demonstrativ den Saal - allerdings nicht Ernst Reuter und Louise Schröder. Vgl. Tümmler, „Deutschland, Deutschland über alles“, S. $16 \mathrm{ff}$.

150 Archiv der Gegenwart, Deutschland 1949-1999, Bd. 3, S. 2496.

151 Zit. nach Wengst, Thomas Dehler, S. 177. 
stehenden Nationalsozialismus" gewesen sei ${ }^{152}$, die rechtzeitig zum Absterben gebracht worden war. Ein Zeichen wurde auch dadurch gesetzt, daß die FDP-Parteiführung eine Bundestagskandidatur des Politikers Ernst Achenbach, der Naumann verteidigte und sich auch ansonsten auffällig für ehemalige Nationalsozialisten einsetzte, im Sommer 1953 verhinderte, und daß der nordrhein-westfälische Innenminister Franz Meyers Naumann nach dessen Haftentlassung per Entnazifizierungsbescheid als „belastet“ einstufte, ihm damit das aktive und passive Wahlrecht entzog und eine Bundestagskandidatur für die rechtsradikale DRP verwehrte ${ }^{153}$. Auch wenn die Aktion Naumann offensichtlich ganz auf das Konto der Briten ging, hatte die Bundesregierung mit der Besatzungsmacht letztlich "gemeinsame Sache“ gemacht ${ }^{154}$; denn vor den anstehenden Bundestagswahlen kam Adenauer eine Schwächung jener Kräfte sehr gelegen, die aus der FDP - mit Unterstützung „Ehemaliger“ - eine große Sammlungsbewegung rechts von der Union machen wollten.

Ein noch stärkeres Zeichen für die „Grenzen der Integration" 155 Ehemaliger hatte die Bundesregierung bereits gesetzt, nachdem Generalmajor a.D. Ernst-Otto Remer ${ }^{156}$ im niedersächsischen Landtagswahlkampf 1951 für die rechtsextremistische Sozialistische Reichspartei aufgetreten war und die Männer des Widerstands als Landesverräter diffamiert hatte. Denn jetzt strengte die Regierung nicht nur ein erfolgreiches Verbotsverfahren gegen die SRP vor dem gerade konstituierten Bundesverfassungsgericht an, sondern auch Remer selbst wurde in einem von Fritz Bauer zum Forum zeitgeschichtlicher Aufklärung erhobenen Prozeß zu drei Jahren Gefängnis verurteilt. Die maßgebliche Initiative zu dem Verfahren war vom CDU-Bundesinnenminister Robert Lehr ausgegangen, der selbst in Verbindung zum 20. Juli gestanden hatte.

In den Kontext der Distanzierung vom Nationalsozialismus einzuordnen ist auch eine frühe Kabinettserklärung aus dem Jahr $1951 \mathrm{zu}$ dem in der Bevölkerung und vor allem bei den Soldatenverbänden noch außerordentlich umstrittenen Attentat des 20. Juli 1944. Die Widerstandskämpfer, so hieß es, hätten „in sittlichem und vaterländischen Pflichtgefühl das Letzte“ versucht, „um Deutschland zu retten oder zumindest das Ausmaß der Katastrophe zu mindern ...". Es sei demnach eine Ehrenpflicht des deutschen Volkes, für die Witwen und Waisen der Männer zu sorgen, die „im Kampf gegen Hitler“ ihr Leben geopfert hatten ${ }^{157}$. Um aufgetretene Härten bei

152 Ebd., S. 179.

153 Frei, Vergangenheitspolitik, S. 391.

154 Ebd., S. 390.

155 So der Titel eines Aufsatzes, der die Problematik am Beispiel der CSU-Personalpolitik thematisiert: Schlemmer, Grenzen der Integration.

156 Er war als Kommandeur des Wachbataillons Großdeutschland am 20. Juli 1944 maßgeblich am Niederschlagen des Aufstands beteiligt gewesen.

${ }^{157}$ Frankfurter Neue Presse, 3. Oktober 1951. 
Pensionsregelungen von Hinterbliebenen der Widerstandskämpfer zumindest symbolisch auszugleichen, ließ Bonn dem „Hilfswerk 20. Juli“ eine symbolträchtige Spende zukommen. Auf Vorschlag des Ministerialrates im Bundeskanzleramt Ernst Wirmer, dessen Bruder von den Nationalsozialisten ermordet worden war, wurde auch bei den rechtlich im einzelnen sehr komplizierten Wiedergutmachungsansprüchen 158 eine Lösung gefunden, die zeigte, „daß man von staatlicher Seite die Opfer der Widerstandstat des 20. Juli - nicht zuletzt mit Blick auf die Außenwirkung dieses, anderen Deutschland' - keineswegs negieren wollte oder konnte."159

Der Sensibilität der Bundesregierung - und des Bundespräsidenten - für das Andenken des 20. Juli korrespondierten Aktivitäten zur allgemeinen historischen Aufklärung über den Nationalsozialismus, etwa durch das 1949 gegründete Institut für Zeitgeschichte oder die 1953 ins Leben gerufene Bundeszentrale für den Heimatdienst (später für politische Bildung). Bereits 1952 wurde in Anwesenheit des Bundespräsidenten und des stellvertretenden Präsidenten des Jüdischen Weltkongresses eine Gedenkstätte in Bergen-Belsen eingeweiht ${ }^{160}$. Gestrenge Beobachter haben zwar eingewandt, daß „mit der Eloquenz und Autorität des Bundespräsidenten allein“ oder auch mit geeigneten Lehrplänen und Gedenkstätten „die Auseinandersetzung mit dem millionenfachen Mord ... nicht zu leisten“ gewesen sei - als ob es dabei geblieben wäre -, und daß insgesamt die „Bekenntnisse und Beschwörungen der Politiker in Sachen Nationalsozialismus“ als „vielfach nur oratorische Leistungen“ geringzuschätzen seien, weil der „offiziellen Feierlichkeit ... die Tabuisierung des Themas im Alltag gegenüber“ gestanden habe und die Erinnerung an den Nationalsozialismus ritualisiert gewesen sei 161 . Vor dem aufschlußreichen Hintergrund der japanischen Entwicklung fragt man sich aber schon, ob ein derart dezidiertes Negativurteil angemessen ist ${ }^{162}$.

Gewiß, die Distanzierung der westdeutschen classe politique - einschließlich der die Regierung führenden Unionsparteien - von dem Unrechtssystem des Dritten Reiches nahm rasch „rituelle“ Züge an. Aber es waren doch Rituale, hinter denen Überzeugungen standen und die einen wesentlichen Beitrag zur ideellen Staatsgründung der Bundesrepublik lieferten.

158 Etwa im Hinblick auf die als Ausschlußgrund wirkende Mitgliedschaft von Männern des 20. Juli in der NSDAP.

159 Toyka-Scid, Gralshüter, Notgemeinschaft oder gesellschaftliche „Pressure-Group“?, S. 205.

160 Heuss mahnte u. a., die Deutschen dürften nie vergessen, „was von Menschen ihrer Volkszugehörigkeit in dicsen schamreichen Jahren geschah“. Konzentrationslager Bergen-Belsen. Berichte und Dokumente, S. $253 \mathrm{f}$.

161 So Benz, Zum Umgang mit der nationalsozialistischen Vergangenheit, S. 53 f., 57.

162 Zumal es sich ausdrücklich auch auf die nicht wissenschaftlich fundierte, sondern politisch motivierte Polemik Ralph Giordanos über die „zweite Schuld“ der bundesdeutschen Verdrängungsgesellschaft nach 1949 - als „moralische Position mit hohem Stellenwert im öffentlich-politischen Diskurs“ - beruft. Ebd., S. 53, Anm. 14. 
Durch ihre Gedenkkultur „bekannte sich die westdeutsche Demokratie in ihrem Selbstverständnis bewußt zum Erbe des Nationalsozialismus"163, distanzierte sich normativ von der Diktatur und verlieh der neuen politischen Ordnung Legitimität. Ohne dieses „ritualisierte“ Gedenken hätte die Auseinandersetzung der bundesdeutschen Gesellschaft mit der nationalsozialistischen Vergangenheit einen ganz anderen, deutlich unbefriedigenderen Charakter angenommen. Einige kontrafaktische Überlegungen mögen dies - vor dem Hintergrund der realen japanischen Entwicklung nach 1945 verdeutlichen.

Man stelle sich etwa vor, in der Bundesrepublik wäre nicht auf die Verleihung von Orden zur Anerkennung militärischer Verdienste im Zweiten Weltkrieg verzichtet worden und auch nicht auf die Bezeichnung „Deutsches Reich" für das neue demokratische Staatswesen. Wie hätte sich die bundesdeutsche Erinnerungskultur entwickelt, wenn darüber hinaus vielleicht gar der Sedanstag oder zumindest der Reichsgründungstag in den offiziellen Gedenkkanon Eingang gefunden hätten und wenn große Gedenkstätten vor allem für die Luftkriegs- oder Vertreibungsopfer entstanden wären, während der Staat z.B. die ehemaligen Konzentrationslager Dachau oder Bergen-Belsen völlig der Vergessenheit hätte anheim fallen lassen, statt die Initiativen ehemaliger Häftlinge aufzugreifen und sic als Gedenkstätten zu pflegen ${ }^{164}$ ? All dies hätte den unbestreitbaren, demoskopisch immer wie-

163 Baumgärtner, Reden nach Hitler, S. 341.

164 Wie schwierig dieser Weg auch in Westdeutschland war, zeigt die Geschichte des ehemaligen Konzentrationslagers Dachau, das die staatlichen Bchörden ab 1948 zu einer Wohnsiedlung für deutsche Vertriebene aus dem Osten umbauen ließen. Eine am „Tag der Opfer des Faschismus“ im September 1950 im Krematorium eröffnete Ausstellung wurde auf öffentlichen Druck hin 1953 wieder geschlossen. Doch die populistische Forderung etwa des stellvertretenden Ministerpräsidenten der damaligen Viererkoalition Josef Baumgartner (Bayernpartei) auf dem Dachauer Volksfest im August 1955, das Krematorium müsse verschwinden, um mit der „Diffamierung des Dachauer Landes“ Schluß zu machen, erfüllte sich nicht. Zum einen, weil ein Zusatzabkommen zu den Pariser Verträgen die Grabstätten von Opfern des NS-Regimes für unantastbar erklärte, zum anderen wegen der Aktivitäten von Häftlingsorganisationen, eine würdige Mahn- und Gedenkstätte zu errichten, die 1960 zu einem provisorischen Museum, 1965 dann zur Eröffnung einer Gedenkstätte mit Museum führten. Ermöglicht hatte dies wesentlich auch die tatkräftige Unterstützung des Vorhabens durch den ehemaligen Dachau-Häftling und CSU-Politiker Alois Hundhammer, „der als langjähriges Mitglied der bayerischen Regierung hohes Ansehen und erheblichen Einfluß genoß “. Marcuse, Das ehemalige Konzentrationslager, S. 194, 199. Vgl. auch Marcuse, Legacies of Dachau.

Das 1946 auf Anordnung der britischen Militärverwaltung eingerichtete Mahnmal BergenBelsen wurde 1952 in die Obhut des Landes Niedersachsen übergeben und offiziell eingeweiht. Ein Dokumentenhaus zur Geschichte des Lagers folgte 1966. (Vgl. Konzentrationslager Bergen-Belsen, S. $235 \mathrm{ff}$.) Offensichtlich wich die Entwicklung der bundesdeutschen Gedenkstätten schon deshalb von der Situation in Japan ab, weil es dort im Inland keine großen authentischen Opferorte gab; allerdings läßt die Art und Weise, wie die Erinnerung an die 20000 koreanischen Opfer des Atombombenangriffs auf Hiroshima "gepflegt" wurde - für die man im Friedenspark selbst bis in die 1990er Jahre hinein keine Gedenkstätte zuließ (vgl. Buruma, Erbschaft, S. 125f.) -, kaum die Vermutung zu, daß sich dies maßgeblich auf die „Vergangenheitsbewältigung“ im Lande ausgewirkt hätte. 
der ermittelten Hang breiter Schichten der Bevölkerung zum Vergessen und Verdrängen des überwundenen Regimes und seiner Verbrechen gewiß auch in der Bundesrepublik entscheidend verstärkt und zu wesentlich größeren Defiziten im Prozeß der „Vergangenheitsbewältigung“ geführt, als sie tatsächlich zu beklagen waren. Wenn man also fragt, welche „inneren“, politisch-kulturellen Faktoren - jenseits des divergierenden Außendrucks - zu den Unterschieden zwischen deutscher und japanischer Erinnerungskultur wesentlich beigetragen haben, kann die Schlüsselfunktion der jeweils führenden politischen Parteien kaum überschätzt werden ${ }^{165}$.

\section{Linksopposition und Pazifismus}

$\mathrm{Zu}$ den Gründen für die vergleichsweise günstige Entwicklung der Erinnerungskultur in Westdeutschland gehört zwar maßgeblich die Neupositionierung des bundespolitisch von 1949 bis 1969 führenden deutschen „Konservativismus", dessen Abkehr von nationalistischen Verirrungen und Läuterung hin $\mathrm{zu}$ internationalen Idealen ungleich deutlicher ausfiel als die seines japanischen Pendants. Kaum weniger wichtig aber war es, daß die (linke) Opposition in der Bundesrepublik in Fragen der „Vergangenheitsbewältigung" viel mehr Gewicht auf die Waage brachte als jene in Japan. Gewiß, auch deutsche Sozialdemokraten waren in den frühen 1950er Jahren zeitweilig vom „Gnadenfieber" befallen. Ausgerechnet ein SPD-Bürgermeister zog bekanntlich im Herbst 1951 in Stadtoldendorf den demonstrativsten Schlußstrich unter die Entnazifizierung, indem er die Akten in den Ofen des städtischen Gaswerkes warf. Für den ersten Nachkriegsvorsitzenden der SPD, Kurt Schumacher, der sich persönlich wegen seines mutigen Eintretens gegen die NSDAP schon vor 1933 und seiner jahrelangen KZHaft danach nichts vorzuwerfen hatte, in seiner skeptischen Haltung gegen die - wie er meinte - kapitalistisch-klerikale Integration Westeuropas nach 1945 indes manchmal nationalistisch wirkte, galt das Wort Walter Dirks, er sei „in Unschuld verstockt"166. Andererseits blieb es eben diesem Schumacher vorbehalten, der stark auf die aktuellen materiellen Herausforderungen bundesdeutscher Politik konzentrierten Regierungserklärung Adenauers im September 1949 entgegenzutreten, weil sie in ihren Passagen „über die furchtbare Tragödie der Juden ... zu schwach“ gewesen sei ${ }^{167}$. Zudem war ganz unübersehbar, daß Sozialdemokraten bald zu einer treibenden Kraft

165 Etwas holzschnittartig ist dagegen die These, kritische Journalisten und Intellektuelle seien auf der einen Seite gestanden, auf der anderen „die konservative Bundesregierung, deren Vergangenheitspolitik von der Mehrheit der Bevölkerung unterstützt wurde“. Frei, Karrieren im Zwielicht, S. 301.

166 Frankfurter Hefte, 3/1950, S. 543.

167 Reichel, Vergangenheitsbewältigung, S. 83. 
der „Vergangenheitsbewältigung“ wurden, sei es aus Überzeugung, weil sie vom NS-Terror noch häufiger und stärker persönlich betroffen gewesen waren als die Christdemokraten, sei es darüber hinaus aus taktischen Erwägungen, weil sie sich ein wenig Konjunktur für ihr mühsames Oppositionsgeschäft gegen den Patriarchen Adenauer versprachen, wenn sie bei passender Gelegenheit „Fälle“ von „Ehemaligen“ publizistisch hochzogen, deren Karrieren im unionsgeführten Regierungs- und Staatsapparat angesichts ihrer Belastung aus dem Dritten Reich wirklich oder vermeintlich zu weit gegangen waren.

In Japan dagegen löste die Wiederkehr der „Ehemaligen“ selbst bei den Linksparteien „keine moralische Entrüstung aus“168, teils aus Furcht, durch einen Verstoß gegen den gesellschaftlichen Schweigekonsens die Chancen auf einen Ausbruch aus dem 30\%-Turm noch weiter zu schmälern, teils wohl auch, weil sie die im Volksglauben allgemein verbreitete Vorstellung teilten, jeder Mensch könne nun einmal - wie in eine Naturkatastrophe - in schicksalhafte Verstrickungen hineingeraten, sich aber danach auch ändern. "Ostasiatische Völker vergessen schneller als europäische", hat Hans Wilhelm Vahlefeld das Phänomen des unterschiedlichen Vergangenheitsbezugs der japanischen und deutschen Gesellschaft auf den Begriff zu bringen versucht ${ }^{169}$. Hinzu kam allerdings, daß „nationalistischer Geist“ sich in Japan keineswegs auf die (extreme) Rechte beschränkte. Selbst die Kommunisten gingen hier einen „Weg ohne Peking und Moskau" 170 und wiederholten den Slogan „Für das Vaterland und das Volk“ lange Zeit wie „ihr Vaterunser"171. Auch bei den Sozialisten als der größten Partei auf der Linken herrschte das Gefühl, die komplette Unterordnung unter die US-amerikanische Politik schade der Nationalmoral ${ }^{172}$, wobei sich dieses Verständnis von Patriotismus mit einem stark ausgeprägten Pazifismus fest verband.

Anders als die Konservativen hatten die japanischen Linksparteien den im Zuge der „Vergangenheitsbewältigung“ in breiten Bevölkerungskreisen vollzogenen Wertewandel vom Militarismus zum Pazifismus nicht nur selbst verinnerlicht; sie waren auch bereit, ihn konsequenter in operative Politik umzusetzen. So zählebig die alten nationalen und religiösen Werte den Bruch von 1945 ansonsten vielfach überdauerten, in der Einstellung zu Krieg und Frieden sollte sich tatsächlich auf breiter Front Entscheidendes ändern, wenn auch die Gründe für diese Entwicklung schwer zu gewichten sind. Zum einen war der gesellschaftliche Nimbus der bis dahin als quasi

168 Vgl. Erlinghaben, Japan, S. 72.

169 Vahlefeld, Japan, S. 279. Mit wieviel Vorsicht derartige Völkerpsychologie zu interpretieren ist, zeigt aber schon der Blick etwa auf die koreanische Opfernation, die keineswegs schnell vergessen hat, was ihr von den japanischen Nachbarn angetan worden war.

170 So auch der Untertitel der Studie von M. Pohl, Die Kommunistische Partei Japans.

171 Mishima, Generationswechsel, S. 348.

172 Hicks, Japan's War Memories, S. 20. 
unbesiegbar geltenden kaiserlichen Soldaten durch die Niederlage im Kern getroffen und hatte die Bekämpfung des Militarismus von Anfang an im Zentrum der amerikanischen Besatzungspolitik gestanden. Zum anderen aber - und dies dürfte im Blick auf die Entwicklung der japanischen Friedensbewegung noch wichtiger gewesen sein - hatte sich die Katastrophe von Hiroshima und Nagasaki aufs tiefste ins politische Bewußtsein des Volkes eingebrannt. Nicht aus einer kritischen Auseinandersetzung mit den Verbrechen der eigenen Armee also wuchs der japanische Nachkriegspazifismus vor allem, sondern aus der Erinnerung an die eigene Rolle als erstes Opfer der Atomwaffen ${ }^{173}$.

Daran änderten auch Bücher z.B. von Gomikawa Jumpei und Tominaga Shozo wenig, die mit Berichten über japanische Kriegsverbrechen in China - nicht zuletzt über die verbreitete Abhärtung von Rekruten durch den Initiationsritus des Köpfens von mindestens einem Gefangenen durch das Schwert - in den Jahren 1956 und 1957 die Öffentlichkeit schockierten ${ }^{174}$. Der Bewältigungsschub war dadurch ausgelöst worden, daß ein Jahrzehnt nach Kriegsende japanische Soldaten aus chinesischer Kriegsgefangenschaft heimkehrten und ihre Erlebnisse nicht selten publizierten. Eine Dokumentation unter dem Titel Sankô, der auf einen chinesischen Begriff für die Politik des „alles umbringen, alles verbrennen, alles plündern“ zurückgeht, fand in zwei Monaten nicht nur mehr als 50000 Käufer, sondern auch ein sehr kritisches Echo, das „hysterische Ausmaße“ annahm. Auf massiven Druck der extremen Rechten erging schließlich ein Verkaufsverbot. Doch die kritischen Heimkehrer ließen sich durch diesen Vorfall nicht zum Schweigen bringen; einige von ihnen gründeten vielmehr die „Vereinigung der China-Rückkehrer“, die schon 1958 mit neuen atemverschlagenden Bekenntnissen über Massaker an der Zivilbevölkerung aufhorchen ließ ${ }^{175}$. Ihre Publikationen dokumentieren, wie vielschichtig auch der japanische Erinnerungsdiskurs verlief 176 .

Charakteristischer waren aber doch Aktivitäten wie die des Japanischen Vereins zum Gedenken an gefallene studentische Soldaten, bekannt unter dem Namen Wadatsumikai. Der Verein entstand in der pazifistischen Bewegung der frühen 1950er Jahre und setzte sich zum Ziel, das Andenken der im Dezember 1943 zwangsweise eingezogenen Studenten zu pflegen, die für die Front gänzlich unvorbereitet - bei Japans letzten, teilweise selbstmörderischen Angriffen buchstäblich verheizt worden waren. In der Erinnerungskultur des Landes lebten die rächenden Seelen dieser gefallenen Stu-

$173 \mathrm{Zu}$ den historischen Wurzeln des japanischen Pazifismus, der an der Wende zum 20. Jahrhundert maßgeblich durch die christliche Minderheit geprägt worden war, vgl. Zahl, Die politische Elite Japans, S. $196 \mathrm{f}$.

174 Hicks, Japan's War Memories, S. 26.

175 Buchholz, Demokratisierung der Erinnerung, S. $46 \mathrm{f}$.

176 Dies betont auch Conrad, Erinnerungspolitik in Japan, S. 7. 
denten in der Luft, im Meer und in den Bergen und riefen die Irdischen auf, sich dem Frieden zu widmen, um eine Wiederholung des tragischen $\mathrm{Ge}$ schehens zu verhindern. Für viele Japaner hatte diese Interpretation der Kriegstoten eine hohe Bedeutung, „denn sie gab der Niederlage einen Sinn als Weg zu einem neuen Japan, das von ,Frieden und Demokratie‘ gekennzeichnet war, dem Mantra der Nachkriegsjahre. “177

Nachdem sich bereits gegen den „ungleichen" Sicherheitsvertrag mit den USA 1952 erbitterter und gewalttätiger Protest geregt hatte und dann immer wieder gegen amerikanische Militärstützpunkte demonstriert worden war, führte der Strahlentod des Funkers eines japanischen Fischereiboots, das vom Fallout der ersten Wasserstoffbombenexplosion der USA auf dem Bikini-Atoll eingeholt worden war, 1954/55 zu einer gewaltigen Welle des Widerstandes gegen die militärische Nutzung der Atomenergie. Auf Initiative einer Gruppe japanischer Frauen wurden bemerkenswerte 30 Millionen Unterschriften für die Ächtung von A- und H-Waffen gesammelt. In dieser Zeit kam, im November 1954, nicht nur der Science-Fiction-Film Godzilla in die Kinos, in dessen Mittelpunkt ein Monster stand, das infolge ciner nuklearen Katastrophe entstanden war; auch anspruchsvollere Filme griffen die Angst vor der atomaren Vernichtung auf. Ebenso wurden ein Friedensmuseum und ein Friedenspark in Hiroshima 1955 eingeweiht ${ }^{178}$. Selbst die beiden konservativ beherrschten Häuser des Parlaments sowie 42 Präfekturversammlungen sahen sich veranlaßt, eine Erklärung zur Ächtung von A- und H-Waffen zu verabschieden.

Dennoch begann die Regierung im Ergebnis des Mutual Security Act (MSA)-Abkommens mit den USA vom Juni 1954 mit der Bildung von „Selbstverteidigungsstreitkräften" 179 . Zwar entsprach Tokio nicht dem ursprünglichen, vom Korea-Krieg ausgelösten Wunsch Washingtons, eine Truppe von 300000 bis 350000 Mann aufzustellen. Doch auch die zugesagte 180000 Mann starke Armee war schwerlich mit Artikel 9 der Verfassung zu vereinbaren, selbst wenn einige kosmetische Maßnahmen dies verdecken sollten. So wurde auf die Schaffung eines nominellen Verteidigungsministeriums zugunsten einer "Agentur für Selbstverteidigung" verzichtet und auch kein Verteidigungsminister berufen, sondern die Führung der Behörde einem „Generaldirektor" übertragen. Den Grundstock der „Selbstverteidigungsstreitkräfte" hatte die 75000 Mann starke „Nationale Polizeireserve“ gelegt, die bereits nach dem Ausbruch des Koreakrieges 1950 aufgebaut worden war. Veteranen der Kaiserlichen Armee, darunter die dienstältesten Ex-Offiziere, wurden von der Regierung zu Tausenden aufgefordert, sich zur Verfügung zu stellen, und bildeten bald das Rückgrat der Truppe. Der

177 Seraphim, Im Dialog mit den Kriegstoten, S. 19.

178 Dower, The Bombed, S. 291.

179 R. Hartmann, Geschichte des modernen Japan, S. $235 \mathrm{ff}$. 
Wiederaufbau der Marine wurde Admiral Nomura Kichisaburo anvertraut, der zum Zeitpunkt des Angriffs auf Pearl Harbor japanischer Botschafter in den USA gewesen und mit größter Wahrscheinlichkeit „für die tödliche Verzögerung der japanischen Kriegserklärung verantwortlich" war ${ }^{180}$.

Über ein halbes Jahrzehnt danach, 1960, löste abermals eine sicherheitspolitische Frage die bis dahin schwerste Krise der japanischen Nachkriegszeit aus. Ursache der Auseinandersetzungen war das Bemühen der Regierung, den „ungleichen“ Sicherheitsvertrag von $1952 \mathrm{zu}$ revidieren, der es den USA unter anderem erlaubte, im Falle von inneren Unruhen in Japan einzugreifen sowie Atomwaffen dort zu stationieren, ohne im Gegenzug eine besondere Verantwortung der USA zur Verteidigung Japans gegen einen Angriff von dritter Seite festzuschreiben ${ }^{181}$. Im Rahmen einer Revision dieses Vertrages hoffte die Regierung Kishi beide Länder als gleichberechtigte Partner zu definieren und wechselseitige Beistandsverpflichtungen zu verankern. Japan sollte so wieder in den Rang der führenden Nation Ostasiens gehoben werden.

Obwohl von Kishis Initiative zunächst keineswegs angetan, gingen die USA unter dem Eindruck des Sputnik-Schocks und der heftigen Opposition gegen die amerikanischen Militärbasen auf Okinawa teilweise darauf ein. Die Eisenhower-Administration erklärte sich bereit, die gewünschte Beistandsverpflichtung im Falle eines Angriffs von außen abzugeben, und sie verzichtete vor allem auch auf ihr Interventionsrecht in Japan. Der am 19. Januar 1960 in Washington unterzeichnete revidierte Sicherheitsvertrag führte aber nicht zu vollständiger Gleichberechtigung zwischen beiden Ländern, sondern ging inhaltlich weiterhin von Japan als einem strategischen Außenposten der USA aus. Ein von Sozialisten dominierter „Volksrat" nahm den Kampf nicht nur gegen diesen "ungleichen“, sondern auch gegen jedweden anderen gleichberechtigten Sicherheitspakt auf, konnte die Revision des Vertrages aber auch mit Hilfe mehrerer Generalstreiks, an denen über fünf Millionen Japaner teilnahmen, und einem Sit-in der linken Abgeordneten im Parlament schließlich nicht verhindern ${ }^{182}$. Auf der anderen Seite gelang es auch den Konservativen jetzt und später nicht mehr, darüber hinaus den Friedensartikel der Verfassung im Sinne größerer militärpolitischer Flexibilität zu ändern.

Vor dem Hintergrund der ohnehin beträchtlichen Schwierigkeiten mit dem pazifistischen Potential im Lande wird plausibel, weshalb die herrschenden Konservativen der Versuchung widerstanden, die Erinnerung an Hiroshima zur Betonung der japanischen Opferrolle stärker zu pflegen. Ganz im Gegenteil wurde die Frage der Entschädigung und medizinischen

180 Harries, Sheathing the Sword, S. 235, 238 (Zitat).

$181 \mathrm{Vgl}$. hierzu Igarashi, Bodies of Memory, S. $133 \mathrm{f}$.

182 Ebd., S. 135. 
Versorgung der Betroffenen lange Zeit nicht befriedigend gelöst ${ }^{183}$. Mußte eine andere, an den Opfern orientierte Politik nicht die Verbesserung der Beziehungen zu Washington erschweren? Und manifestierte sich nicht in der Asche von Hiroshima das Versagen des viel beschworenen japanischen Geistes vor der überlegenen westlichen Technologie - ein Versagen, an das man ungern erinnert werden wollte? Jedenfalls hatte wenige Tage nach der Explosion der Atombomben 1945 eine führende Zeitung geschrieben: „Wir haben gegen die Wissenschaft des Feindes verloren"184. Selbst die starke, LDP-geführte Regierung sah sich indes außerstande, die Erinnerung an Hiroshima dauerhaft zu ignorieren; zumal die politische Linke mit dem „Japanischen Rat gegen Atom- und Wasserstoffbomben" eine bald von der KP dominierte Bürgerbewegung schuf. Um das Thema nicht dem gegnerischen Lager zu überlassen, konterte die LDP 1961 mit der Gründung eines „Volksrates für Frieden und gegen Kernwaffen“, doch dauerte es noch einmal fast zehn Jahre, bis 1970 Satô als erster Premierminister Hiroshima besuchte. Satô prägte bei diesem Anlaß den Topos von "Japan als erstem und einzigen Land, das von der Atombombe getroffen wurde“. Scine Argumentation, Japan sei durch die Atombomben „zumindest in gleichem, wenn nicht in weit höherem Ausmaß ein Opfer von, Verbrechen gegen die Menschlichkeit" " geworden, als es „je Täter eines solchen Verbrechens in den von ihm besetzten Ländern hätte sein können“, war aber in der öffentlichen Debatte schon seit den 1950er Jahren „nicht selten auch explizit“ als "Gegenrechnung" aufgemacht worden ${ }^{185}$.

Die Gefühle von über dreihunderttausend Überlebenden der Atombombenabwürfe und ihre gesamtgesellschaftlichen Auswirkungen bildeten schon früh einen gewichtigen friedenspolitischen Faktor. Nach einer Umfrage der Asabi sprachen sich 1968 nur 19 Prozent der Befragten für eine Änderung des Antikriegsartikels der Verfassung aus, während 64 Prozent dagegen waren. Noch etwas höher sogar fiel der Anteil jener aus, die den amerikanischen Nuklearschirm für eine Bedrohung ihres Landes hielten. Die Zahlen verwundern kaum, wenn man bedenkt, daß ziemlich genau 50 Prozent selbst die Führung eines Verteidigungskrieges für unzulässig hielten ${ }^{186}$. In bezug auf das Militär fiel die „Vergangenheitsbewältigung“ in Japan während der ersten beiden Dekaden nach 1945 also um einiges radikaler aus als in der Bundesrepublik, was sich übrigens auch in einem nicht einmal halb so hohen Anteil der japanischen Verteidigungsausgaben am Gesamthaushalt ausdrückte. Zwar hatten beide Völker Millionen Soldaten und Zi-

183 Vgl. auch Dower, The Bombed, S. 284.

184 Zit. nach Coulmas, Japanische Zeiten, S. 190. Zur Bedeutung Hiroshimas für die japanische Erinnerungskultur vgl. auch Schwentker, Täter oder Opfer?, vor allem S. 157 ff., sowie Hogan, Hiroshima in History and Memory, und Yoneyama, Hiroshima Traces.

185 Hijiya-Kirschnereit, „Kriegsschuld, Nachkriegsschuld“, S. 332.

186 Vgl. Ishida, Japanese Political Culture, S. $128 \mathrm{f}$. 
vilisten im Krieg verloren, doch die alliierten Luftangriffe gegen Dresden und Hamburg hatten - auch angesichts der Vorgeschichte deutscher Bombardements auf Warschau, Rotterdam oder Coventry - erinnerungskulturell keine Wirkung zu entfalten vermocht, die der Schockwirkung der neuartigen Atombomben auf Hiroshima und Nagasaki annähernd vergleichbar gewesen wäre ${ }^{187}$.

Schon im Grundgesetz der Bundesrepublik war 1949 lediglich das individuelle Recht auf Kriegsdienstverweigerung, nicht aber der staatliche Verzicht auf eigene Streitkräfte verankert worden. Als verfassungswidrig stufte Artikel 26 GG Handlungen ein, „die geeignet sind und in der Absicht unternommen werden, das friedliche Zusammenleben der Völker zu stören“; CDU und FDP hatten jedoch mit Verweis auf die Nürnberger Urteile durchgesetzt, daß explizit nur die Vorbereitung eines „Angriffskrieges“ unter Strafandrohung gestellt, die Führung eines Verteidigungskrieges aber nicht ausgeschlossen wurde ${ }^{188}$. An den im Zuge der Wiederbewaffnung nötig werdenden Änderungen, der „Wehrverfassung“, wirkte 1956 die oppositionelle SPD ebenso mit wie vorher schon bei der Gründung des Personalgutachterausschusses, der die einzustellenden Obersten und Generäle auf ihre persönliche Eignung - und nicht zuletzt auf ihre Vergangenheit hin überprüfte. In dem Ausschuß und bei den Vätern der Bundeswehr insgesamt repräsentierte sich "personell nachdrücklich“ das Erbe des Widerstands gegen den Nationalsozialismus ${ }^{189}$. Vielleicht auch deshalb fiel die Opposition gegen die - in linken Gewerkschafts- oder evangelischen Kirchenkreisen polemisch so genannte - „Remilitarisierung“ in der Bundesrepublik insgesamt deutlich schwächer aus als in Japan, obwohl der Protest aus den Sorgen um eine Verewigung der deutschen Teilung potentiell sogar besonders viel - nationale - Nahrung beziehen konnte.

Auf anderen Politikfeldern aber gelang es der erinnerungskulturell engagierten Linken - und einigen mit ihr sympathisierenden Kräften im bürgerlichen Lager ${ }^{190}$ - in Westdeutschland immer wieder, ihre Sorge vor einer Wiederkehr des Vergangenen mit Hilfe wachsamer Journalisten öffentlichkeitswirksam zur Geltung zu bringen und in einigen Fällen Fehlentwicklungen durch publizistischen Protest und Demonstrationen zu korrigieren. Die Kritiker wirklicher oder auch nur vermeintlicher Bewältigungsdefizite profitierten dabei entscheidend von dem in Westdeutschland nach $1945 \mathrm{sehr}$ viel weiter als in Japan gegangenen Wandel des Mediensystems. Ad illu-

187 Der japanische Überfall auf Pear Harbor hatte ebenso noch zu einer anderen Kategorie der Kriegsführung gezählt wie die schweren Luftangriffe amerikanischer Bomber im Frühjahr 1945 auf dic Großstädtc Nagaoka, Kobe oder Tokio.

188 Jahrbuch des öffentlichen Rechts der Gegenwart, Neue Folge/Band 1, 1951, S. 235-243.

189 So zählten im „Amt Blank“ Graf von Schwerin, Johann Adolf Graf von Kielmansegg, Wolf Graf von Baudissin, Axel von dem Bussche und Achim Oster zum ehemaligen Umkreis des Widerstandes. Reichel, Vergangenheitsbewältigung, S. 99.

190 Vgl. hierzu Fröhlich/Kohlstruck (Hg.), Engagierte Demokraten. 
strandi causa sei nur der besonders spektakuläre und frühe Fall des niedersächsischen FDP-Politikers Leonhard Schlüter im Juni 1955 erwähnt, der bei der Bildung einer neuen Koalition aus CDU, DP, BHE und FDP zum Kultusminister ernannt worden war.

$\mathrm{Da}$ in einem Verlag Schlüters unlängst Bücher des ersten Gestapo-Chefs sowie des Hauptschriftleiters des SS- „Ahnenerbes“ erschienen waren, traten Rektor und Senat der Universität Göttingen aus Sorge um Entwicklung und Ansehen der deutschen Hochschulen im Ausland demonstrativ zurïck. Studenten brachten vor dem Auditorium Maximum Schriftblöcke „Schlüter" mit SS-Runen an. Die örtlichen Parteien von der SPD bis zur CDU unterstützten den Protest ebenso wie gesellschaftliche Gruppen vom DGB bis zum Ensemble des „Deutschen Theaters“. Nationale und internationale Presse verstärkten den Druck derart, daß Schlüter schon nach wenigen Wochen zurücktreten mußte ${ }^{191}$.

Der in diesem Fall und bei vielen ähnlichen Anlässen ziemlich breite gesellschaftliche Konsens bezüglich der Abwehr neonazistischer Tendenzen, der häufig auf Initiative von links zustande kam, hat seinen Teil dazu beigetragen, die „schleichende Machtübernahme“192 durch ehemalige Nationalsozialisten zu verhindern - eine Entwicklung, wie sie übervorsichtige Journalisten des Bayerischen Rundfunks in einer Radio-Sendung Mitte 1955 als Schreckgespenst für die Bundesrepublik an die Wand gemalt hatten. Daß demgegenüber in Japan Repräsentanten des vergangenen ultranationalistischen Regimes häufiger an die Schalthebel von Politik, Wirtschaft und Gesellschaft gelangten, hing nicht zum wenigsten mit der Schwäche der permanenten Opposition zusammen, die Politikwissenschaftler dazu veranlaßt hat, von einem „Anderthalb-Parteien-System “ zu sprechen ${ }^{193}$. Die Opposition fand zwar im Protest gegen neuerliche militaristische Tendenzen - oder dem, was sie dafür hielt - breiteren gesellschaftlichen Rückhalt, nicht aber in der Kritik an Defiziten der nationalen Erinnerungskultur. Den im Sinne der „Vergangenheitsbewältigung" engagierten Bürgern in der frühen Bundesrepublik wurde ihre Arbeit allerdings auch dadurch erleichtert, daß sie bei Bedarf immer wieder von außen durch die internationale Öffentlichkeit Unterstützung erfuhren.

191 Eine eingehende Analyse des Falles Schlüter bei Marten, Der niedersächsische Ministersturz.

192 Vgl. den Bericht in der Süddeutschen Zeitung vom 10. Juni 1955 sowie Hammerschmidt/ Mansfeld, Der Kurs ist falsch, S. 54.

193 So T'suneishi, Japanese Political Style, S. 124. Die herrschende LDP habe die Macht monopolisiert und als einzige gewußt, wie man regiert, während dic Opposition als permanente Minorität zeitweise regelrecht Angst vor der Macht gehabt zu haben scheine. Ähnliches läßt sich von der SPD in der Bundesrepublik nicht behaupten. Auch wenn sie erst 1966, nach über anderthalb Jahrzehnten Oppositionsarbeit, als Juniorpartner an einer Bundesregierung beteiligt wurde, regierte sie vorher doch zahlreiche, auch wichtige Länder und übte so auf dem Wege des Bundesrates einigen Einfluß aus. 